The University of Maine

DigitalCommons@UMaine

Student Work

Fall 9-2-2021

\title{
Lateral Spreading and Stability of Embankments Supported on Fractured Unreinforced High-Modulus Columns
}

\author{
Aaron P. Gallant \\ University of Maine, aaron.gallant@maine.edu \\ Danilo Botero Lopez \\ University of Maine, danilo.botero@maine.edu
}

Follow this and additional works at: https://digitalcommons.library.umaine.edu/student_work

Part of the Geotechnical Engineering Commons

\section{Repository Citation \\ Gallant, A. P. \& Botero-Lopez, D.. (2021), Lateral Spreading and Stability of Embankments Supported on Fractured Unreinforced High-Modulus Columns. DFI Journal - The Journal of the Deep Foundations Institute, 15(2). 10.37308/DFIJnl.20201015.226}

This Published Paper is brought to you for free and open access by DigitalCommons@UMaine. It has been accepted for inclusion in Student Work by an authorized administrator of DigitalCommons@UMaine. For more information, please contact um.library.technical.services@maine.edu. 


\title{
Lateral Spreading and Stability of Embankments Supported on Fractured Unreinforced High-Modulus Columns
}

\author{
Aaron P. Gallant ${ }^{1 *}$ and Danilo Botero-Lopez ${ }^{2}$
}

\begin{abstract}
Construction of column-supported embankments (CSEs) with unreinforced high-modulus elements is now common practice to accelerate fill placement. These brittle columns are susceptible to column fracturing and CSE designs often limit the degree of lateral spreading such that tensile rupture will not occur, which stems from salient concerns that fracturing may trigger uncontrolled lateral spreading and/or the cessation of intended vertical load transfer. However, tensile rupture is unlikely to coincide with full mobilization of available passive resistance at the toe. Thus, it is disputed in industry whether some degree of column fracturing is tolerable. The objective of this study is to elucidate the influence of column fracturing on lateral spreading and stability of CSEs. A collective examination of available performance data is accompanied by a parametric 3D finite element study of hypothetical embankments, which considers the cessation of column bending resistance due to tensile rupture at discrete crack locations. A factor of safety of safety, which reflects uncontrolled lateral spreading that arises at the embankment toe after development of a passive failure block in surficial crust, is proposed. Factors of safety are linked to the magnitude of lateral spreading to address whether adequate confinement can be provided by foundation soils when fracturing occurs in unreinforced high-modulus columns that support embankments.
\end{abstract}

\section{Keywords: column supported embankments, high-modulus columns, column fracturing, crust, lateral spreading}

\section{Introduction}

When project schedules govern the rate of embankment construction, column-supported embankments (CSEs) are justified to facilitate accelerated placement of fill if alternative methods (e.g. pre-loading, staged-filling, prefabricated vertical drains, etc.) do not attenuate issues concerning i.) deformations beneath the fill and adjacent facilities and/or ii.) stability of the embankment. Arching is the vertical load transfer mechanism largely responsible for transferring the embankment load into the

\footnotetext{
${ }^{1}$ Assistant Professor, University of Maine, Orono, ME 04469, USA, aaron.gallant@maine.edu

${ }^{2}$ Graduate Student, University of Maine, Orono, ME 04469, USA, danilo.botero@maine.edu

*Corresponding author: aaron.gallant@maine.edu
} 
columns and reducing stress imparted on foundation materials beneath the embankment. In some cases, a pile cap or a geosynthetic-reinforced load transfer platform (LTP) is incorporated at the base of the fill to increase the efficacy of load transfer. The mechanics of vertical load transfer are well-established and have been the subject of many theoretical and experimental investigations (e.g. Filz et al., 2019; Guido, 1987; Hewlett \& Randolph, 1988; Hong et al., 2007; King et al., 2017; Liu et al., 2017; McGuire et al., 2020; McGuire, 2011; Russell et al., 2003; Russell \& Pierpoint, 1997; Sloan et al., 2013; Van Eekelen et al., 2013, 2015; Yun-Min et al., 2008). Previous full-scale CSE studies have relied on field performance data (e.g. Almeida et al., 2015; Briançon \& Simon, 2012; King et al., 2018; Lin \& Wong, 1999; Liu et al., 2015, 2009, 2012; Wang \& Zhang, 2020; Wu et al., 2019), often in combination with numerical analyses (e.g. Chai et al., 2019, 2015; Hosseinpour et al., 2019; Jamsawang et al., 2019; Liu et al., 2007; Nunez et al., 2013; Stewart et al., 2004; Voottipruex et al., 2011; Wu et al., 2019), to assess performance. These efforts have contributed, by in large, to a greater understanding of a CSE's ability to alleviate stress imparted by the embankment on the foundation soils.

As a portion of the embankment load is carried by the foundation soils, some lateral spreading and bending of the perimeter columns occurs. If stresses imposed on foundation materials are not adequately reduced, loss of confinement at the embankment toe can lead to basal instability (e.g. Chai et al., 2019; Wang \& Zhang, 2020) - a topic that has received considerably less attention. Earlier CSEs, often referred to as "pile-supported"” embankments, used steel piles, precast reinforced concrete piles, or timber piles that can resist relatively large lateral loads in bending (e.g. Gartung et al., 1996; Hoppe et al., 2006; Hsi, 2001; Wachman et al., 2010). Construction and economic efficiencies shifted industry towards the use of "ground improvement" methods to provide column-support, such as deep mixing methods or aggregate columns (e.g. Almeida et al., 2015; Broms, 2003; Deb \& Mohapatra, 2013; Goughnour \& Barksdale, 1984; Kitazume \& Maruyama, 2006; Lin \& Wong, 1999; Stewart et al., 2004; Voottipruex et al., 2011). Today, it is common practice to support embankments on unreinforced cement-based grouted elements that are constructed with a hollow-stem drilled-displacement (DD) tool, continuous flight auger (CFA), vibro concrete method (VCM), or similar; whereby a cylindrical cavity is created at depth and grout is injected to cast a concrete column as the ground penetration tool is withdrawn from the hole. These brittle elements are commonly referred to as "high-modulus" columns. The role of lateral spreading, particularly as it applies to bending and potential fracturing, remains a salient concern.

In practice, designers often utilize area replacement ratios that limit lateral spreading and tensile rupture of high-modulus columns (i.e. formation of cracks) in bending, as it has been suggested by some that column fracturing should be avoided (Chai et al., 2017; Kitazume \& Maruyama, 2007; Wang \& Zhang, 
2020; Yapage et al., 2014). For taller embankments, prescribing to a design constraint that precludes column fracturing may require a.) area replacement ratios that make high-modulus columns costprohibitive or b.) addition of steel reinforcement to increase bending resistance near the embankment perimeter, making them less efficient to construct. This design constraint stems from concerns that the cessation of column bending resistance may trigger excessive lateral spreading and the loss of toe confinement. However, unreinforced high-modulus elements are several orders of magnitude stiffer than the foundation materials, and it is unlikely that fracturing coincides with full mobilization of passive resistance at the toe. Thus, it is disputed in industry whether unreinforced high-modulus columns can tolerate some degree of crack development and safely support taller embankments, because the consequences of column fracturing, with respect to lateral confinement and basal stability, are poorly understood.

The objectives of this study are to: i.) establish the role of column fracturing on lateral instability; and ii.) address whether adequate factors of safety can be achieved when column fracturing occurs. A collective assessment of available performance data reported in case histories is first presented to provide some precedent for the magnitude of lateral spreading that typically occurs and to emphasize the influence of a stiff surficial crust on performance. This assessment is followed by a 3D finite element study of hypothetical embankments, where a method to account for the cessation of column bending resistance due to tensile rupture is incorporated to faithfully assess the system response. The progression of column cracking beneath an embankment and its influence on lateral spreading and vertical load transfer into the columns is presented to establish the influence of column fracturing on performance, followed by a parametric study where factors of safety against loss of toe confinement are linked to the magnitude of lateral spreading. A methodology to assess the factor of safety based on mobilized passive resistance at the toe is proposed and extracted from the 3D finite element analyses to reflect the anticipated mode of basal instability and to overcome limitations of existing limit equilibrium methods commonly adopted in practice to address lateral spreading and global stability. The influence of area replacement, geosyntheticreinforcement, crust thickness, and soft soil thickness are examined and implications for design and construction are discussed.

\section{Field observations from case histories}

Case history information was limited to studies of column-supported systems where lateral deformations $\left(\delta_{\mathrm{h}}\right)$ were monitored with inclinometers near the toe of an embankment or perimeter of a mechanically stabilized earth (MSE) wall, which were also a proxy for mobilized passive resistance in the 
foundation materials. Two cases where failure occurred were also documented. Though this study focused on CSE systems supported on high-modulus columns, lateral spreading data for embankments supported on low-modulus columns were also collected to supplement the case history inventory, as load sharing by the foundation soils is governed by the same vertical load transfer mechanisms and available data for highmodulus columns were limited.

\section{Case History Information}

Table 1 summarizes the case history information and Figure 1 shows the terminology adopted in this study. For each case, embankment and CSE details, including fill height $(H)$, slope $(n)$, column type (high-modulus - HM or low-modulus - LM), column penetration through the soft soil (floating-FT, full penetration-FP, or embedment in a bearing layer-EB), column area replacement ratio $(\alpha)$ and spacing $(s)$, and stiffness $(J)$ of geosynthetic reinforcement in the LTP (if applicable) were identified. In some cases, the unit weight of the fill varied significantly. For example, in the study by Almeida et al., (2015), the fill was composed of sinter feed with an exceptionally high unit weight of $27.8 \mathrm{kN} / \mathrm{m}^{3}$. Therefore, an "equivalent" embankment height $\left(H_{e}\right)$ was applied to all cases using a unit weight of 20 $\mathrm{kN} / \mathrm{m}^{3}$ (see notes in Table 1). All lateral deformations were measured within one column spacing of the embankment toe or MSE wall perimeter.

Table 1 also indicates the soil type and thickness of a stiffer surficial layer $\left(H_{l}\right)$, referred to herein as "crust," overlying soft soil of thickness $H_{2}$. Thickness of the crust was classified based on a clear transition in material type to underlying softer material. Granular soil/fill with a stiffness $E<5 \mathrm{MPa}$ was classified as "loose" while $E \geq 5 \mathrm{MPa}$ was classified as "dense." When $H_{1}$ was comprised of fine-grained soil, it was classified based on the overconsolidation ratio (OCR). Lightly overconsolidated (LOC) and heavily overconsolidated (HOC) materials were classified as having an OCR less than and greater than four, respectively. When this information was not reported, the surficial material type was interpreted with available subsurface information (e.g. cone penetration tests or the liquidity index) or additional references associated with a study were consulted. The water content $(\omega)$ and undrained shear strength $\left(s_{u}\right)$ of the soft soil is also summarized in Table 1. 
Table 1. Summary of CSE details and subsurface conditions for the case history inventory where lateral deformations were documented

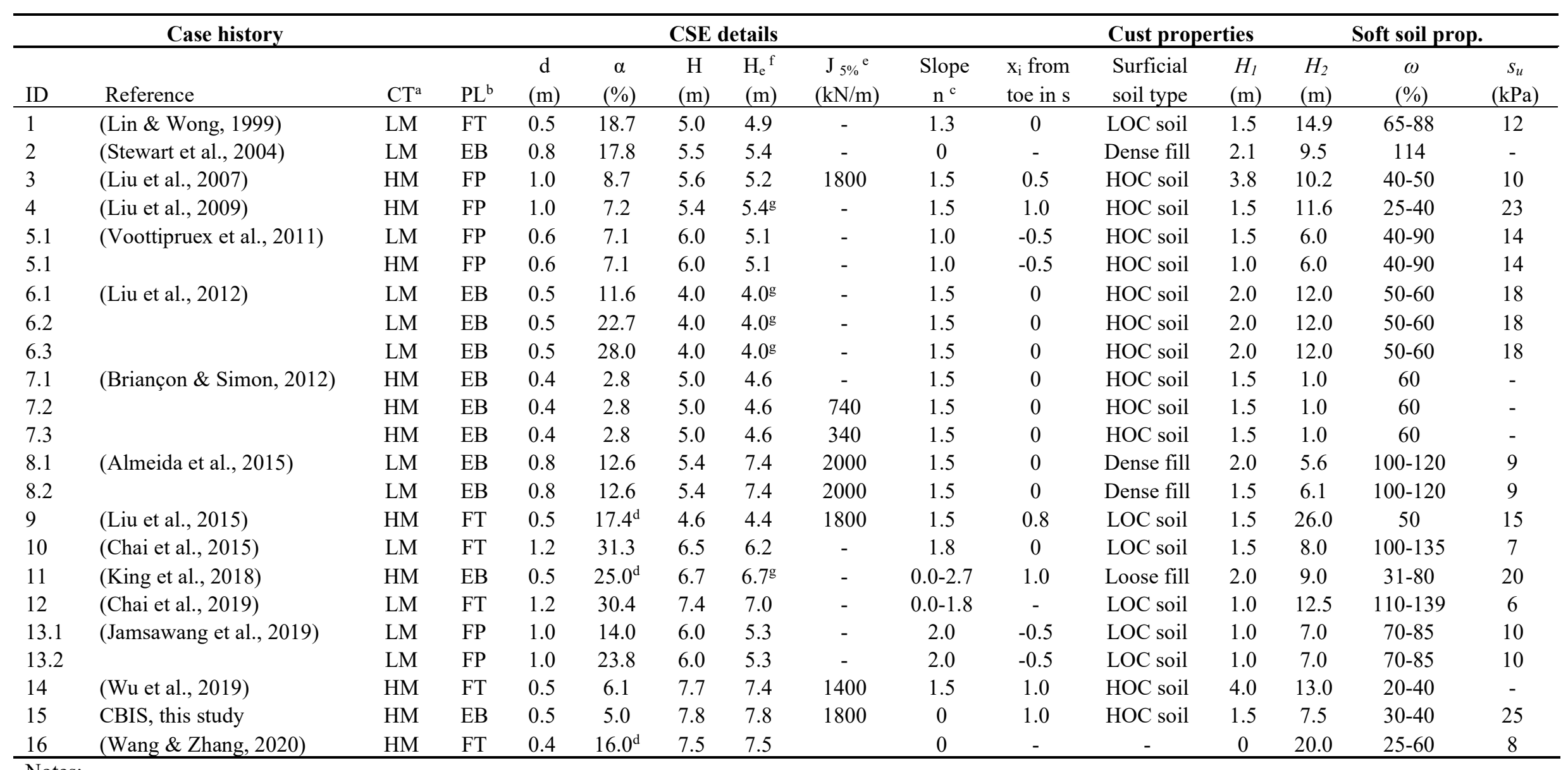

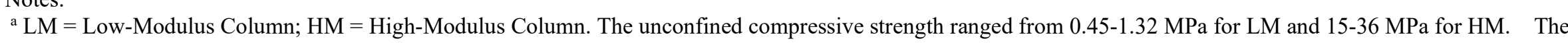
column stiffness varied from 0.04-0.13 GPa for LM, and 19-38 GPa for HM.

${ }^{\mathrm{b}} \mathrm{PL}=$ Penetration length of the columns; FT = Floating; FP = Full penetration; $\mathrm{EB}=$ embedded

${ }^{\mathrm{c}} \mathrm{n}=$ horizontal distance for 1 unit of vertical distance shown in Figure 1

${ }^{\mathrm{d}}$ Cases with caps

e $\mathrm{J}=$ tensile stiffness of the geosynthetic

${ }^{\mathrm{f}}$ An "Equivalent" embankment height, $H_{e}=\left(\gamma_{f i l l} H\right) / \gamma_{20}$, where $\gamma_{20}=20 \mathrm{kN} / \mathrm{m}^{3}$, was applied to all studies.

${ }^{\mathrm{g}}$ Unit weight of the fill for case IDs 4,6 , and 11 was not reported and $\gamma_{\text {fill }}=20 \mathrm{k} \mathrm{kN} / \mathrm{m}^{3}$ was assumed. 


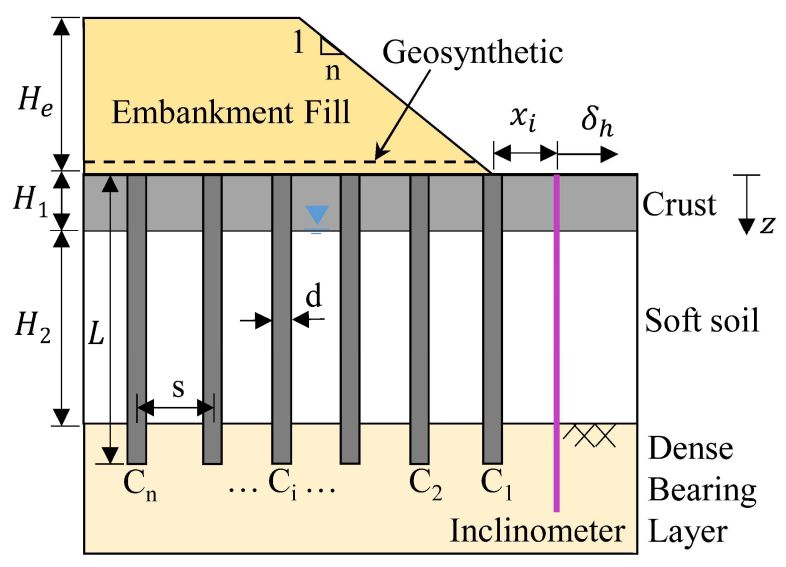

Figure 1. Terminology for geometry of a CSE system, subsoil conditions, and inclinometer location shown in Table 1.

\section{Distribution of Lateral Movements and Influence of a Surficial Crust}

Lateral spreading in the foundation soils were examined at depth to understand the influence of the crust material and column penetration length. Figure 2 shows the distribution of lateral displacements at depth, where displacements are normalized by the maximum movement $\left(\delta_{h} / \delta_{h, \max }\right)$ and depth is normalized by the column length $(z / L)$. Floating systems (Figure 2a) may exhibit a significant degree of relatively uniform deep-seated lateral spreading as the embankment load is not transferred through the columns to a stiff bearing layer below the tips of the columns $(z / L>1)$. Movements below the tips of the columns were limited for cases where columns extended to, or were embedded in, a substantially stiffer soil (Figure 2b,c). For these cases, lateral displacements generally decrease with depth toward the column tips, though the largest lateral deformations did not always occur at the ground surface $(z / L=0)$. 


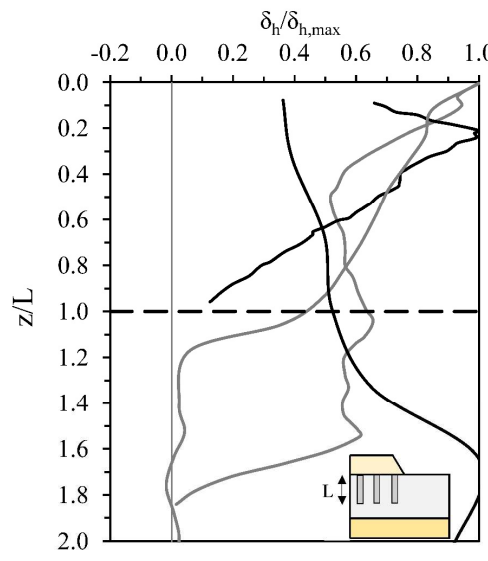

(a)

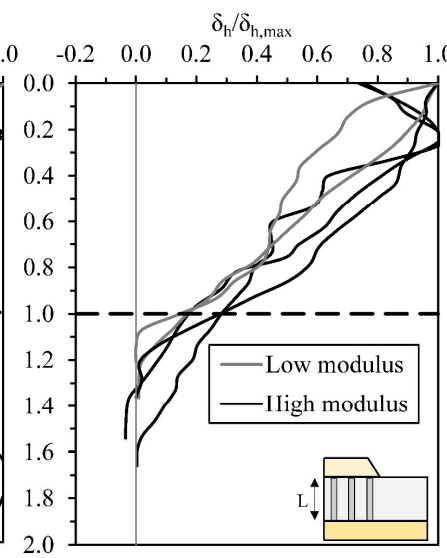

(b)

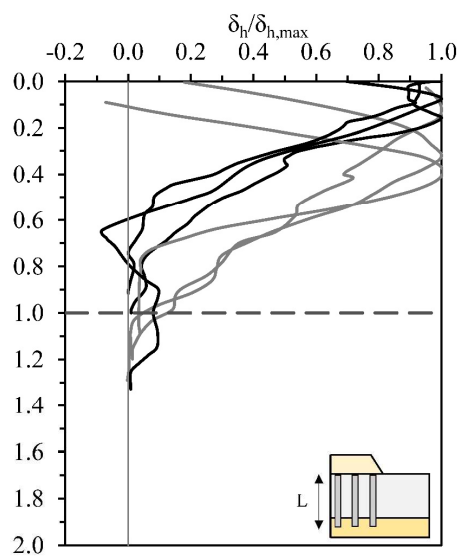

(c)

Figure 2. Distribution of normalized lateral deformations measured with inclinometers at depth: a.) floating columns; b.) full penetration columns; and c.) embedded columns

Figure 3 shows the distribution of lateral movements with depth normalized by the thickness of the crust $\left(z / H_{1}\right)$. When the crust consisted of dense granular soil or HOC clay (Figure 3a), the largest deformations occurred at depths near, or below, the bottom of the crust $\left(z / H_{1}=1\right)$. This indicates that potential slip surfaces begin developing at depth and that a stronger/stiffer crust "braced" the embankment toe near the ground surface, where the magnitude of lateral spreading was less. Notably, the distribution of movements were akin to those observed for internally-braced or tied-back excavations when external lateral supports are installed early on during an excavation to control lateral deformations (Clough, 1990; Hsieh \& Ou, 1998). This analogy is useful for considering the role of of the crust with regards to confinement, as lateral spreading is mitigated by the crust, so long as it does not yield (elaborated on more later in the numerical study). Though the degree of restraint provided at the toe by a stiff crust varied-due to variability in relative crust thickness with respect to the embankment height and relative stiffness between the crust and underlying softer soil- the general response holds true irrespective of column stiffness (LM vs. HM). When the crust consisted of LOC clay or loose granular soils, the largest lateral movements occurred at the ground surface, with the exceptions of ID 9, which had a cap and was floating (Figure 3b). Though surficial LOC clays and loose granular fills were identified as transitional soils to the softer material below, there is a distinct difference in the distribution of lateral movements at shallow depths relative to stiffer crust soils. 


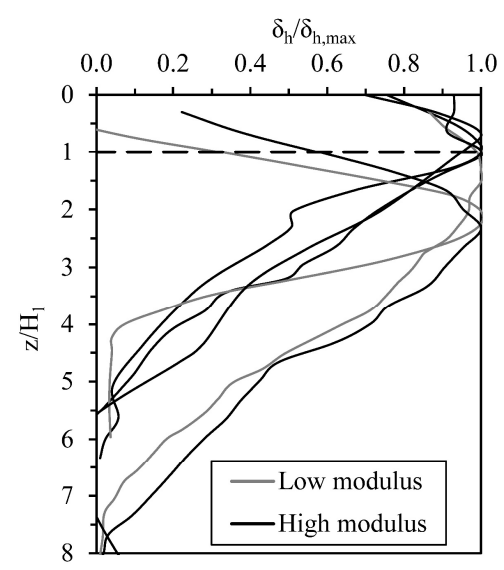

(a)

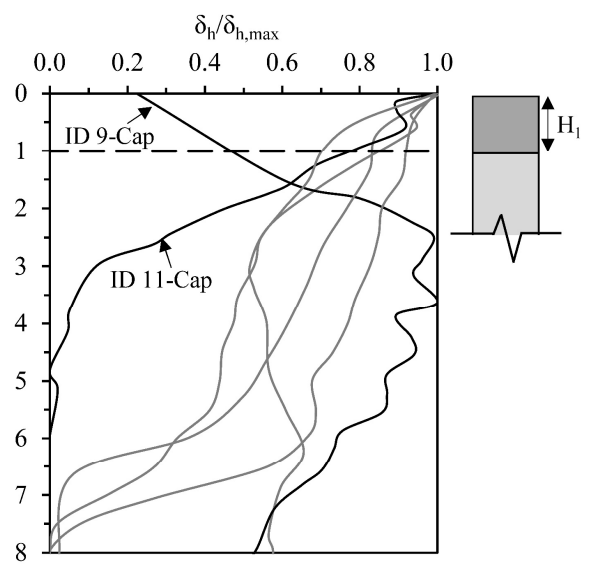

(b)

Figure 3. Influence of surficial soil type on the distribution of lateral deformations for: a.) heavily overconsolidated clays or dense granular soil; and b.) lightly overconsolidated clay or loose granular soil

\section{Magnitude of Lateral Spreading}

Figure 4 summarizes the maximum normalized lateral displacements $\left(\delta_{h, \max } / H_{e}\right)$ observed for column-supported systems. The equivalent embankment heights ranged between 4.0 and $7.8 \mathrm{~m}$ and documented area replacement ratios for CSEs with high-modulus columns (focus of this study) ranged between 2.8 and $8.7 \%$, with the exception of cases 9, 11, and 16, which had caps (Figure 4a). The majority of observed normalized displacements were less than $1 \%$ ( 11 of 16 cases), and less than $2 \%$ for all cases where basal instability did not occur (cases $12 \mathrm{f}$ and $16 \mathrm{f}$ indicated with red arrows). Normalized displacements were less than $0.6 \%$ for all CSEs supported on high-modulus columns that were not floating.

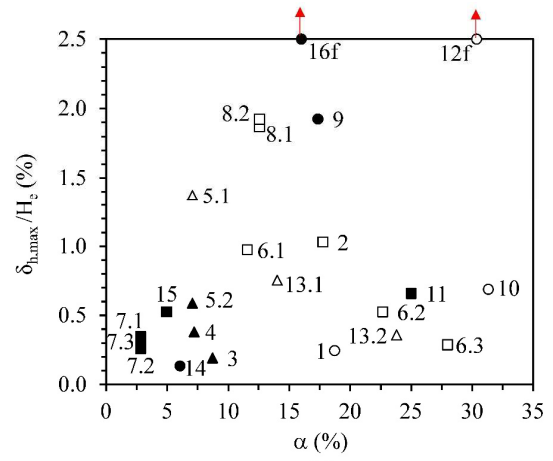

(a)

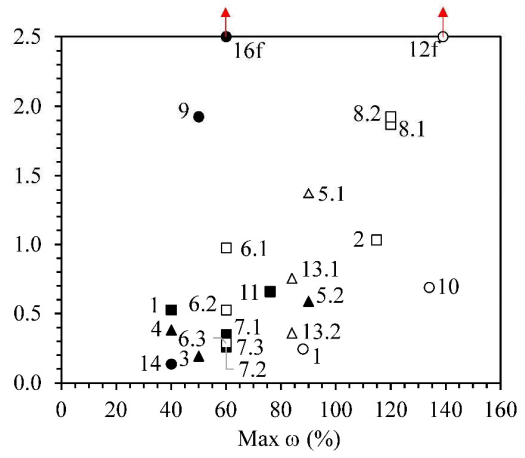

(b)

$$
\begin{array}{|ll|}
\hline \text { Open: Low modulus } & \text { o Floating } \\
\text { Closed: High modulus } & \Delta \text { Full penetration } \\
& \square \text { Embedded } \\
\hline
\end{array}
$$

Notes:

ID 9,11 , and $16 \mathrm{f}$ columns have a cap, ID $12 \mathrm{f}$ and $16 \mathrm{f}$ are failure cases.

Figure 4. Summary of normalized maximum lateral displacements documented for CSEs where the corresponding ID numbers from Table 1 are indicated. Normalized displacements are compared with: a.) area replacement ratio; b.) maximum water content in the soft soil; c.) normalized thickness of the crust 
The relative thickness of the crust $\left(H_{1} / H_{e}\right)$ was generally lower for cases where softer soil conditions (i.e. higher $\omega$ ) were encountered, and accompanied by greater normalized displacements (Figure 4b). Lower normalized displacements generally corresponded to increasing crust thickness (Figure 4c). Notably, normalized thickness of the crust was lowest for the two cases where lateral spreading progressed to basal instability and failure of the column-supported system (IDs 12 and 16). However, it should also be recognized that cases 12 and 16 were floating systems and the columns did not extend to a substantially stiffer layer. Floating systems are less common ( 6 of the 16 documented cases here) because they reduce stress on the foundation soils less efficiently.

\section{Summary of Observed Trends}

The observed distribution of lateral movements at depth help provide an appreciation for the role that surficial HOC clays and dense granular fills play with regards to toe confinement and the degree of lateral spreading that occurs. The aggregated case history data also demonstrate that the magnitude of lateral

spreading typically observed near the toe of CSEs was less than $1 \%$ for the majority of cases, and less than $0.6 \%$ for CSEs supported on high-modulus elements that were not floating; though the number of cases documented for CSEs supported high-modulus elements was limited. In the succeeding numerical demonstrations, the influence of column fracturing on lateral spreading and basal stability is investigated for a broad range of subsurface conditions.

\section{Finite Element Analyses}

Though the documented field data highlight the subsurface conditions influencing lateral spreading of CSEs, column fracturing was not investigated (or captured explicitly) during these field campaigns. Numerical 3D finite element analyses (FEA), which incorporated a method to account for the cessation of column bending resistance, were conducted to examine the stability and performance of hypothetical CSE systems supported on fractured elements. The range of subsurface conditions and area replacement ratios identified for high-modulus columns (without caps) from the case-history inventory (Table 1) informed the numerical study. A numerical demonstration was performed to explicitly illustrate the influence of column fracturing with and without geosynthetic reinforcement in an LTP on the maintenance of intended vertical load transfer and lateral spreading, followed by a parametric study that examined lateral spreading and mobilization of passive resistance at the toe, which was linked to a factor of safety associated with loss of toe confinement, for a broad range of conditions. The influence of a.) area replacement $(\alpha)$, b.) 
thickness of a stiff surficial layer $\left(H_{1}\right)$, and c.) underlying soft soil thickness $\left(H_{2}\right)$, strength, and stiffness were investigated and compared with the field observations for high-modulus elements.

\section{Model Details}

Numerical analyses were performed using the commercial finite element code Plaxis 3D, version 2020.03. Figure 5a shows the base model geometry and finite element mesh. Staged filling was simulated in $0.25 \mathrm{~m}$ lifts to a maximum height of $5 \mathrm{~m}$. Columns were assumed to have a square-grid arrangement and a half-cell unit width was adopted to take advantage of system symmetry and to decrease the computational expense of each simulation. The columns extended to the toe of the embankment (condition for the majority of cases from the case history inventory) and were embedded $2 \mathrm{~m}$ in a stiff bearing layer that was $4 \mathrm{~m}$ thick.

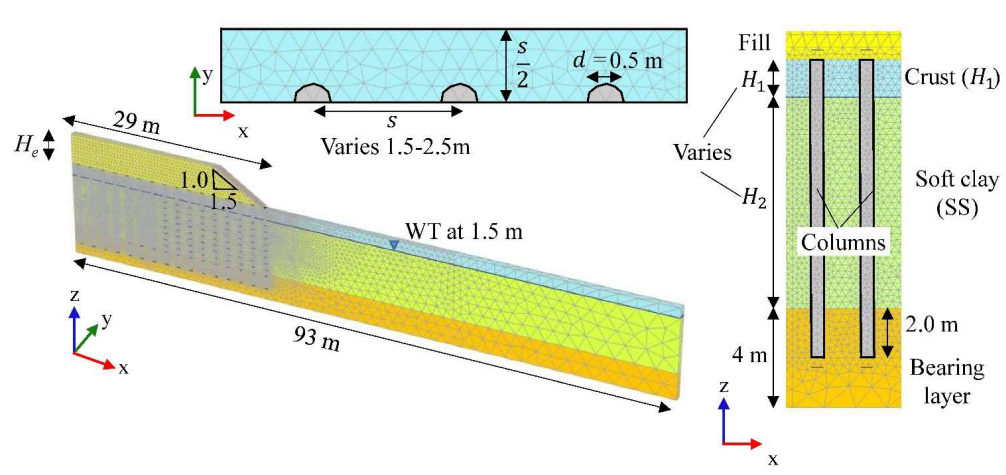

(a)

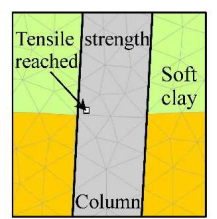

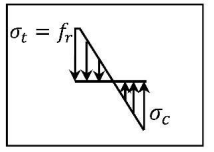

(1)

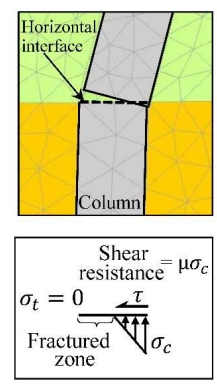

(2)
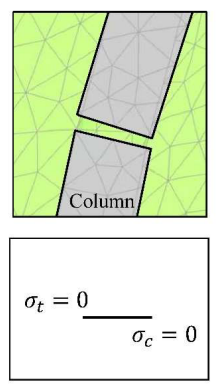

(3)

(b)

Figure 5. (a) Finite element mesh and model geometry considered in finite element analyses. (b) Discrete-crack method to simulate fracturing and stresses in the column: 1.) column remains intact until tensile stresses $\left(\sigma_{t}\right)$ exceeds the modulus of rupture $\left(f_{r}\right) ; 2$.) interface crack elements are introduced upon tensile yielding of the column to simulate a discrete crack, resulting in a redistribution of column stresses at crack locations that depend on the degree of slippage and column rotation; 3.) illustrated separation of the column at fracture locations for large deformations

The subsurface profile consisted of three layers: 1.) a stiff surficial layer of clay crust underlain by 2.) a normally consolidated soft layer of clay, and 3.) a stiff bearing layer of sand (Figure 5a). Both drained and undrained conditions in the crust and soft clay were considered in the parametric study. Table 2 summarizes the constitutive models and parameters for all materials. A Mohr-Coulomb (MC) model was selected to simulate the crust and bearing layer of sand. Stiffness and strength of the crust was representative of a HOC clay soil. The hardening soil (HS) model (Schanz et al., 1999), which accounts for soil's stress-dependent non-linear stiffness, was selected for the fill. The hardening soil model with a 
small-strain stiffness overlay (HSS) was selected for the soft soil layer of clay to account for small-strain stiffness degradation (Benz et al., 2009), which can appreciably influence the predicted magnitude of lateral spreading and degree of mobilized passive resistance in the crust. Three soft soils (SS1, SS2, and SS3) were considered in the parametric study and calibrated to represent the range of soft clay conditions from the case history inventory for high-modulus columns. Details regarding soft soil parameter selection are provided in the notes of Table 2.

Interface elements were applied to the perimeter of all columns to simulate soil-column interface friction $\left(f_{s}\right)$ and capture the subsurface load transfer attributed to downdrag, horizontal drag load on columns due to lateral soils deformations beneath the slope, and axial skin resistance below the neutral plane. For drained analyses, the effective strength parameters for adjacent soil layers were adopted. For undrained analyses, $f_{s}$ was assumed to be $25 \mathrm{kPa}$ in the crust. In the soft clay layer $f_{s}=5+1.5 z \mathrm{kPa}$, where $z$ is depth in meters below the bottom of the embankment.

Table 2. Constitutive models and parameters for soil layers, columns, and interface crack elements

\begin{tabular}{|c|c|c|c|c|c|c|c|c|c|c|c|c|c|c|}
\hline Material & Model & $\begin{array}{c}\gamma \\
(\mathrm{kN} / \mathrm{m})\end{array}$ & $\boldsymbol{k}_{0}$ & $\begin{array}{c}c^{\prime} \\
(\mathrm{kPa})\end{array}$ & $\begin{array}{l}\varphi^{\prime} \\
\left(^{\circ}\right)\end{array}$ & $m$ & $(\mathrm{MPa})$ & $\mathbf{v}$ & $\begin{array}{c}\boldsymbol{E}_{\mathbf{5 0}}^{\boldsymbol{r e f}} \\
(\mathrm{MPa})\end{array}$ & $\begin{array}{c}\boldsymbol{E}_{\text {oed }}^{\text {ref }} \\
(\mathrm{MPa})\end{array}$ & $\begin{array}{c}\boldsymbol{E}_{\boldsymbol{u r}}^{\boldsymbol{r e f}} \\
(\mathrm{MPa})\end{array}$ & $\begin{array}{c}\boldsymbol{G}_{\mathbf{0}}^{\boldsymbol{r e f}} \\
(\mathrm{MPa})\end{array}$ & $\begin{array}{l}\gamma 0.7 \\
(\%)\end{array}$ & $\begin{array}{c}\boldsymbol{f}_{\boldsymbol{r}} \\
(\mathrm{kPa})\end{array}$ \\
\hline Fill & HS & 20 & 0.45 & 0 & 33 & 0.5 & - & 0.20 & 40.0 & 40.0 & 120.0 & - & - & - \\
\hline Crust & & 17 & & 15 & 28 & - & 10 & 0.20 & - & - & - & - & - & - \\
\hline Soft soil $1\left(\mathrm{H}_{2}\right)$ & HSS & 17 & 0.66 & 0 & 20 & 1.0 & - & 0.20 & 1.2 & 0.6 & 7.5 & 7.9 & 0.055 & - \\
\hline Soft soil $2\left(\mathrm{H}_{2}\right)$ & & 17 & 0.53 & 0 & 28 & 1.0 & - & 0.20 & 2.2 & 1.1 & 13.0 & 16.2 & & - \\
\hline Soft soil $3\left(\mathrm{H}_{2}\right)$ & HSS & 17 & 0.50 & 0 & 34 & 1.0 & - & 0.20 & 3.1 & 1.5 & 18.4 & 31.4 & 0.015 & - \\
\hline Dense Sand & $\mathrm{MC}$ & 20 & 0.36 & 0 & 40 & - & 50 & 0.20 & - & - & - & - & - & - \\
\hline Column & $\mathrm{MC}$ & 23 & 0.18 & 4427 & 55 & - & 25000 & 0.18 & - & - & - & - & - & 2800 \\
\hline Crack interface & $\mathrm{MC}$ & 23 & 0.18 & 0 & 22 & - & 500 & 0.18 & - & - & - & - & - & 0 \\
\hline \multicolumn{15}{|c|}{$\begin{array}{l}\text { Notes: Soft soil (SS) parameters were calibrated to be representative of soft cohesive soils documented in the case histories for high- } \\
\text { modulus columns. Water contents ranged between } 20 \% \text { and greater than } 100 \% \text { but were less than } 100 \% \text { for all high modulus cases (see } \\
\text { Table 1). Based on correlations of } C_{c} \text { with water contents by (Azzouz et al., 1976; Lambe \& Whitman, } 1991 \text { ), } \omega=90 \%, 50 \% \text {, and } 35 \% \\
\text { correlate to } C_{c}=1.3,0.5 \text {, and } 0.3 \text {. This information is typically available for CSE projects. These values were chosen to calibrate tangential } \\
1 \mathrm{D} \text { stiffness }\left(E_{\text {oed }}^{r e f} \text { ) for SS1, SS2, and SS3, respectively. Values for } E_{50}^{r e f} \text { were assumed to be twice the value of } E_{\text {oed }}^{r e f} \text {. The value of } E_{u r}^{r e f}\right. \\
\text { was obtained for a ratio of } \kappa / \lambda=0.15 \text { (Terzaghi et al., } 1996 \text { ). Values of } G_{0} \text { were obtained using the relationship proposed by (Hardin } \& \\
\text { Black, } 1969 \text { ) and the shear strain value } \gamma_{0.7} \text { was determined using stiffness degradation curves presented by (Vardanega \& Bolton, } 2013 \text { ). } \\
\text { Effective strength parameters were selected to achieve normalized undrained shear strengths in triaxial compression of } s_{u} / \sigma^{\prime}{ }_{v}=0.25,0.31 \text {, } \\
\text { and } 0.34 \text {, for SS1, SS2, and SS3, respectively. The undrained strength is governed by the HSS model's prediction of excess pore water } \\
\text { pressure. }\end{array}$} \\
\hline
\end{tabular}

Columns were simulated with the MC constitutive model and strength and stiffness parameters were selected to simulate an unconfined compressive strength of $q_{u}=28 \mathrm{MPa}$ for concrete (Table 2). Though a tension cutoff was considered to identify locations along the column where tensile stresses exceeded the modulus of rupture $\left(f_{r}\right)$, it does not capture the energy released due to fracture propagation. Thus, a "discrete-crack" method was adopted to account for the cessation of tensile-resistance at crack locations 
(Maatkamp, 2016). The discrete-crack method introduces interface elements through the column with a predefined orientation (assumed horizontal in this study), as illustrated in Figure 5b. Though this method neglects the energy release rate due to microcracking and fracture propagation (Bazant et al., 1987; Hillerborg et al., 1976), it adequately introduced a constitutive response to assess the global behavior of CSE systems supported on fractured elements.

Interface crack elements were predefined every meter along all columns at depth, but not activated, prior to simulating staged construction of an embankment. Tensile stresses in the columns (if the existed) under combined axial and bending loads due to lateral spreading may be computed as:

$$
\sigma_{t}=\frac{P}{A}+\frac{M}{S}
$$

where $P$ and $M$ are the axial load and moment in the column, and $A$ and $S$ are the column cross-sectional area and section modulus, respectively. After each $0.25 \mathrm{~m}$ increment of filling the tensile stresses in each column were inspected and the nearest interface crack elements were activated to simulate fracturing when tensile stresses exceeded the modulus of rupture. Interface shear resistance at crack locations (in compression) was governed by a Coulomb frictional coefficient of $\mu=0.4$, or $\phi^{\prime}=22^{\circ}$ (Tassios \& Vintzēleou, 1987). Upon activation of interface elements, columns were free to slide, rotate, and, if soil deformations were sufficiently large, separate (Figure 5b). Though predefined crack locations did not always coincide with the exact location of the maximum tensile stress in a column, refinement of available interface crack elements (i.e. closer spacing) had a negligible influence on the computed response.

\section{Column Fracturing, Load Transfer, and Lateral Spreading}

A "progressive crack analysis" was performed for a hypothetical $5 \mathrm{~m}$ embankment to illustrate the locations and progression of column fracturing, as well as its influence on load transfer and lateral spreading. For this demonstration, crust and soft soil thicknesses of $H_{1}=1.5 \mathrm{~m}$ and $H_{2}=8.5 \mathrm{~m}$ were applied, respectively. Soft soil SS2 (Table 2) and undrained conditions were considered. Columns were spaced $2 \mathrm{~m}(\alpha=4.9 \%)$ without geosynthetic reinforcement at the base of the fill.

Figure 6a illustrates the sequence and depth of cracking predicted throughout staged filling of the embankment. Generally, fracturing progressed from columns located nearest the embankment toe to trailing elements beneath the slope. Column fracturing (or rupture) due to bending was first predicted at $H_{e}=2.75 \mathrm{~m}$ in column $C_{1}$ (nearest the toe) at a depth of $z=10 \mathrm{~m}$. This was due to the combination of relatively high unbalanced lateral load and small axial load carried by the perimeter column (equation 1). 
Herein, the fill height associated with the first instance of tensile rupture is referred to as " $H_{r}$." Figure $6 \mathrm{~b}$ shows the significant decrease in tensile stress in the intact portions of $C_{1}$ upon activation of the discretecrack interface elements ( 1 to 2 in the sequence). The change in the column's deformed shape due to rotation after the crack was activiated is only visible with the inset provided in Figure $6 \mathrm{~b}$. At $z=6 \mathrm{~m}$, $\sigma_{t}=0$ in $C_{1}$, not because a crack was imposed, but because there is no bending or curvature in the element at this depth (see deformed shape). Upon increasing the fill height, some columns fractured at secondary locations; once filling progressed to $H_{e}=4.75 \mathrm{~m}$, cracking had occured in $C_{1}$ and $C_{2}$ at $z=2 \mathrm{~m}$. Figure 6c shows the decrease in tensile stresses in the upper portion of $C_{1}$ at $H_{e}=4 \mathrm{~m}$ after a crack was imposed ( 7 to 8 in the sequence). Tensile stresses at greater depths were already reduced due to crack activation earlier in the filling sequence (Figure 6b).

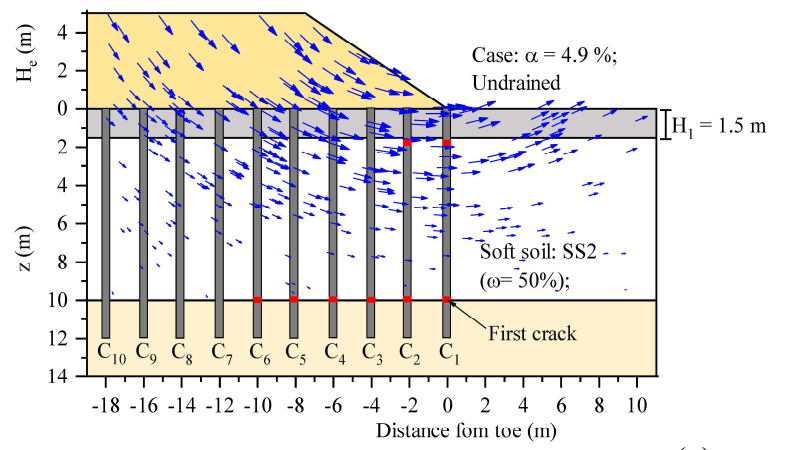

$$
\begin{aligned}
& \text { Sequence: } \\
& \text { 1. } \mathrm{H}_{\mathrm{r}}=2.75 \mathrm{~m} \\
& \text { 2. } \mathrm{C}_{1}(\mathrm{z}=10 \mathrm{~m}) \\
& \text { 3. } \mathrm{H}_{\mathrm{e}}=3.0 \mathrm{~m} \\
& \text { 4. } \mathrm{C}_{2}(\mathrm{z}=10 \mathrm{~m}) \\
& \text { 5. } \mathrm{H}_{\mathrm{e}}=3.5 \mathrm{~m} \\
& \text { 6. } \mathrm{C}_{3}(\mathrm{z}=10 \mathrm{~m}) \\
& \text { 7. } \mathrm{H}_{\mathrm{e}}=4.0 \mathrm{~m}
\end{aligned}
$$

8. $\mathrm{C}_{1}(\mathrm{z}=2 \mathrm{~m}), \mathrm{C}_{4}(\mathrm{z}=10 \mathrm{~m})$

9. $\mathrm{H}_{\mathrm{e}}=4.5 \mathrm{~m}$

10. $\mathrm{C}_{5}(\mathrm{z}=10 \mathrm{~m})$

11. $\mathrm{H}_{\mathrm{e}}=4.75 \mathrm{~m}$

12. $\mathrm{C}_{2}(\mathrm{z}=\mathrm{z}=2 \mathrm{~m}), \mathrm{C}_{6}(\mathrm{z}=10 \mathrm{~m})$

13. $\mathrm{H}_{\mathrm{e}}=5.0 \mathrm{~m}$

(a)

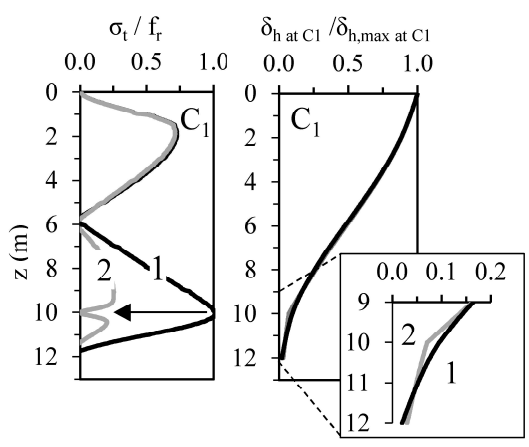

(b)

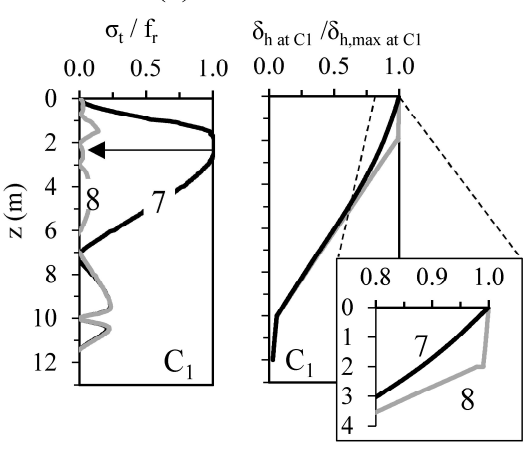

(c)

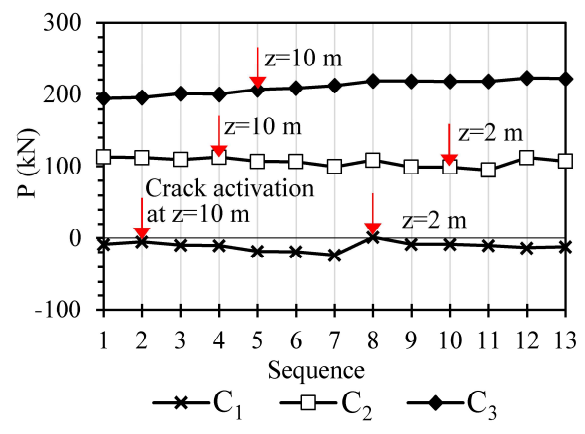

(d)

Figure 6. Locations and progression of column fracturing throughout staged filling of a hypothetical $5 \mathrm{~m}$ embankment subject to undrained conditions: a.) CSE geometry and sequence of fracturing predicted throughout the simulation. Blue arrows illustrate the displacement field at the final embankment height, $H_{e}=5 \mathrm{~m}$; b.) normalized column tension and deformed shape for column $C_{1}$ before and after column fracture at $z=10 \mathrm{~m}$ (1 to 2 in the sequence); c.) normalized column tension and deformed shape for $C_{1}$ before and after column fracture at $z=2 \mathrm{~m}$ ( 7 to 8 in the sequence); d.) computed axial load in columns $C_{1}, C_{2}$, and $C_{3}$ at $z=1.5 \mathrm{~m}$ (bottom of the crust) throughout the progressive crack analysis - where red arrows indicate when a discrete-crack was imposed.

At the final embankment height $\left(H_{e}=5 \mathrm{~m}\right)$ a total of six columns cracked, which was just beyond the crest of the slope. Figure $6 \mathrm{~d}$ shows axial load carried by columns $C_{1}, C_{2}$, and $C_{3}$ at $z=1.5 \mathrm{~m}$ (bottom of 
the crust) as fracturing progressed. Note that the height of the slope over elements $C_{1}, C_{2}$, and $C_{3}$ remained constant after the fracture sequence began (i.e. at $H_{r}=2.75 \mathrm{~m}$ ), and only small changes in axial load were predicted throughout the remainder of the filling sequence. Imposing cracks had no apparent influence on vertical load carried by fractured elements. For instance, when discrete-cracks were imposed in $C_{2}$ (indicated by red arrow in Figure 6d), the axial load remained constant and was unchanged in $C_{3}$. Therefore, any column rotation at fracture locations, which was limited, did not result in a significant redistribution of load or catastrophic loss of intended vertical load transfer as the fill height increased. Thought not shown, axial loads in other trailing elements were also unaffected due to fracturing.

To investigate the influence of bending resistance on the degree lateral spreading and associated mobilization of passive resistance at the toe, three column conditions were considered for the same hypothetical embankment. These column conditions were: i.) an assumed "infinite strength" in bending, whereby a linear elastic material with the stiffness of uncracked concrete was applied to the columns; ii.) cracks develop "progressively" during filling (previous demonstration); and iii.) a more extreme "multicrack" assumption, whereby discrete-cracks were imposed every meter along all columns prior to simulating filling.

Figure 7 shows the computed lateral deformations in the foundation soils one column spacing beyond the toe and aligned with the center of the unit cell (where most inclinometers were placed during field monitoring campaigns summarized earlier). Lateral deformations, a proxy for embankment stresses imposed on foundation soils near the toe of the embankment, indicate a negligible difference for all three column assumptions. Notably, the maximum normalized displacements at $H_{e}=5 \mathrm{~m}$ were nearly $1.2 \%$, which is relatively high based on documented cases (Figure 4). Thus, even for relatively large lateral deformations, the cessation of bending resistance had no apparent influence on load transfer and the magnitude of lateral spreading. Adopting design constraints that prevent column fracturing (i.e. cessation of bending resistance at discrete locations) should imply confinement provided by the foundation soils does not adequately facilitate intended load transfer into the elements and/or that lateral spreading is exacerbated by crack development. The preceding demonstrations have shown this is not the case. 


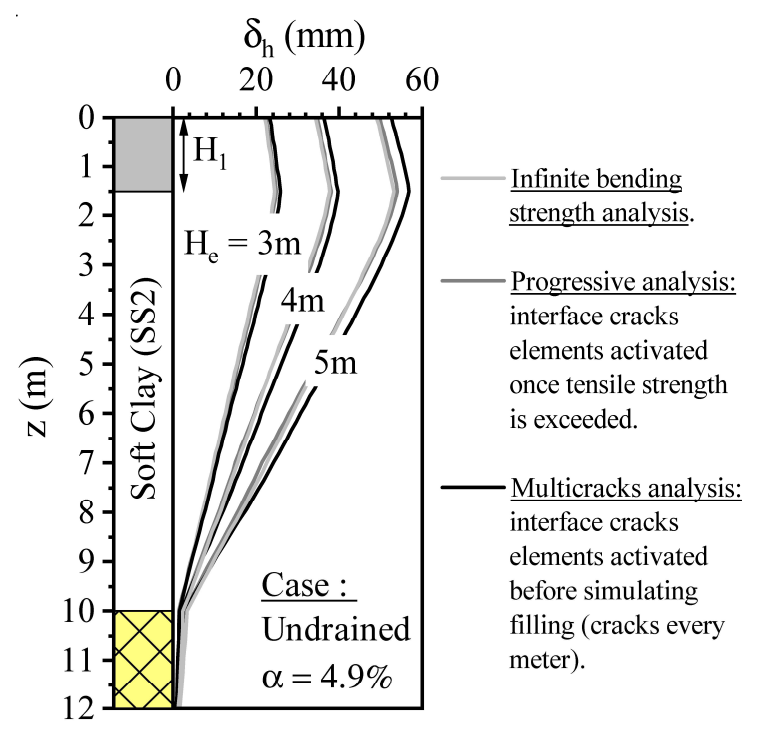

Figure 7. Comparison of computed lateral displacements one column spacing beyond the toe for different column assumptions, which include infinite bending strength, progressive crack analysis, and multicrack analysis for undrained conditions. Note that $\mathrm{s}=2 \mathrm{~m}, H_{1}=1.5 \mathrm{~m}, H_{2}=8.5 \mathrm{~m}$, and SS2 was considered for the soft soil (same conditions as Figure 6)

\section{Geosynthetic-Reinforcement and Column Fracturing:}

Geosynthetic-reinforcement has been incorporated in an LTP at the base of the fill for many embankments supported on high-modulus columns (see Table 1). The addition of tensile reinforcement is often considered a critical component of design because the columns to do not provide adequate lateral resistance to mitigate spreading (Schaefer et al., 2017). However, it was previously demonstrated that the column bending resistance has a negligible influence on the degree of lateral spreading that occurs. The inclusion of geosynthetic reinforcement was investigated to examine its influence on column fracturing and performance for the same hypothetical embankment conditions. A layer of the geosynthetic was simulated $0.4 \mathrm{~m}$ above the base of the fill for geosynthetic stiffnesses of $\mathrm{J}=500-8,000 \mathrm{kN} / \mathrm{m}$. Even though typical geosynthetic stiffnesses vary from $J=500-3,000 \mathrm{kN} / \mathrm{m}$, a value of $8,000 \mathrm{kN} / \mathrm{m}$ was used to simulate the condition where multiple layers of reinforcement are installed, which is a reasonable assumption because the tensile reinforcement in the fill behaves as a system of parallel springs (Van Eekelen \& Bezuijen, 2014).

Figure 8a compares the magnitude of lateral spreading at the toe associated with different fill heights, where simulations were carried out until model convergence could not be achieved due to full mobilization of passive resistance in the crust and failure of the foundation soils occured. Notably, the geosynthetic did not signficantly influence the first instance of column rupture $\left(H_{r}\right.$ in Figure $\left.8 \mathrm{a}\right)$, reduce lateral spreading 
at embankment heights less than $5 \mathrm{~m}$ (previous demonstration), nor significantly alter the fill height associated with the location or number of columns that fractured when $H_{e}=5 \mathrm{~m}$ (Figure $8 \mathrm{~b}$ ). It has been demonstrated by others that engagement of tensile reinforcement requires relatively large deformations (e.g. McGuire et al., 2020, Gallant et al., 2020), and may have limited efficacy with respect to reducing the magnitude of lateral spreading (Briançon \& Simon, 2012).

Without geosynthetic reinforcement, loss of toe confinement and uncontrolled lateral spreading was predicted at $H_{e}=6.5 \mathrm{~m}$ (Figure $8 \mathrm{a}$ ). Higher embankment heights were achieved with stiffer geosyntheticreinforcement, though it did not appreciably engage until passive resistance in the crust was nearly fully mobilized at the toe. Fracturing also continued to progress in columns further behind the toe as the embankment height increased (Figure 8b). Therefore, while geosynthetic reinforcement introduces more ductility to the CSE system, stiffness of the foundation materials, particularly the crust, were largely responsible for governing the fill heights linked to column rupture — not the geosynthetic stiffness. This also cooborates recent finding by others (Yu et al., 2021).

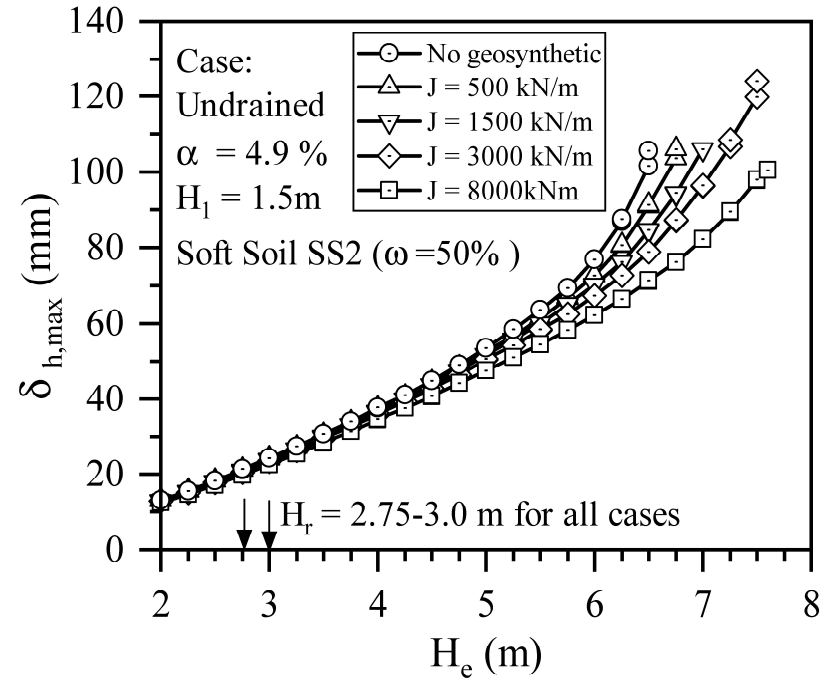

(a)

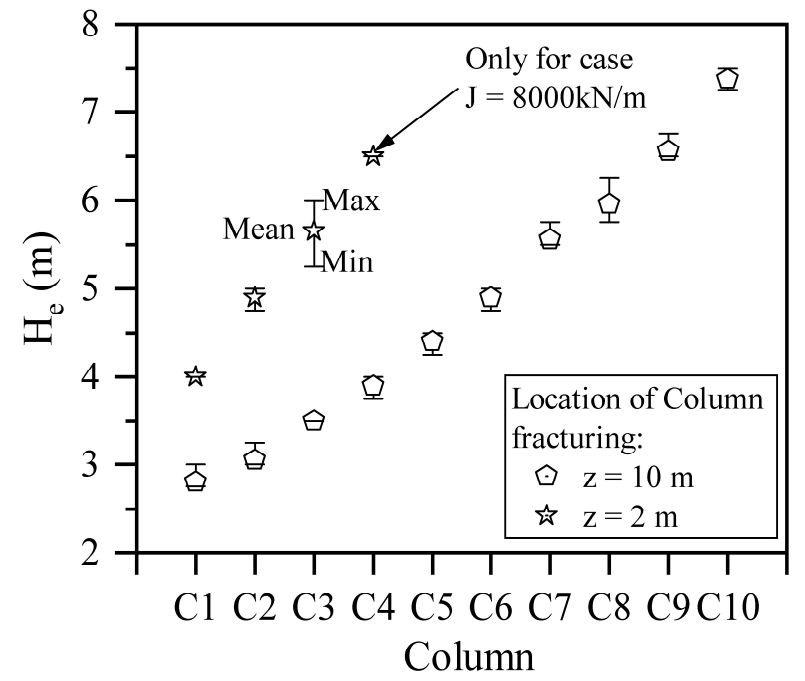

(b)

Figure 8. (a) Computed lateral spreading vs. fill height with and without geosynthetic reinforcement incorporated 0.4 $\mathrm{m}$ above the base of the fill; (b) range of fill heights where column fracturing was predicted at $\mathrm{z}=10$ and $2 \mathrm{~m}$ in columns 1 to 10 for all cases investigated . Note that $\mathrm{s}=2 \mathrm{~m}, \mathrm{H}_{1}=1.5 \mathrm{~m}, \mathrm{H}_{2}=8.5 \mathrm{~m}$, and SS2 was applied to the soft soil (same conditions as Figure 6).

This numerical demonstration emphasized that reliance geosynthetic-reinforcement to mitigate lateral spreading implies relatively large soil deformations will occur before tensile resistance begins to engage; and that column fracturing should be anticipated, which in and of itself does not destabilize the system. The preceding numerical demonstrations illustrated that lateral confinement provided by the foundation soils continued to facilitate maintenance of intended vertical load transfer (Figure 6d) and that column 
bending resistance did not influence the magnitude of lateral spreading associated with mobilization of passive resistance at the toe (Figure 7). Therefore, while column fracturing is a consequence of lateral spreading, the cessation of bending resistance at crack locations does not exacerbate the issue. However, when a geosynthetic-reinforced LTP is not incorporated, assessing the available passive resistance provided by the foundation materials — in particular the crust—becomes a crticial component regarding lateral stability of the CSE system.

\section{Parametric Study}

The succeeding parametric study presented herein was carried out to link the degree of lateral spreading to a factor of safety that reflects the mode of instability in the foundation soils. A broad range of subsurface conditions and column area replacement without geosynthetic reinforcement for hypothetical $5 \mathrm{~m}$ embankments were investigated and two subsurface profiles were considered. The first profile maintained a bearing layer depth $\left(H_{1}+H_{2}\right)$ of $10 \mathrm{~m}$ and the crust $\left(H_{1}\right)$ and soft soil $\left(H_{2}\right)$ thicknesses were varied. The second considered a constant crust thickness of $H_{1}=1.5 \mathrm{~m}$ and varied the soft soil thickness (i.e. depth to the bearing layer varied), to illustrate the effect of decreasing the column length on column fracturing and lateral spreading. All three soft soil types, as well as both drained and undrained limit states, were considered. Recall that the soft soils were calibrated to encapsulate the soft soil conditions documented from the case history inventory for high-modulus columns. Soft soils SS1, SS2, and SS3 were calibrated to reflect materials with water contents of 90,50 , and 35 percent, respectively; i.e. the softest material is SS1 and SS3 was the stiffest soft soil (Table 2). Lateral spreading and factors of safety were evaluated for area replacements of $\alpha=3.1 \%, 4.9 \%, 8.7 \%(s=1.5,2.0$, and $2.5 \mathrm{~m})$.

\section{Lateral Spreading and $\mathrm{H}_{\boldsymbol{r}}$}

The embankment height associated with the first instance of columns rupture, $H_{r}$, is a useful metric to indicate at what stage of embankment filling column fracturing begins. A value of $H_{r} / H_{e}<1$ indicates tensile rupture occured prior to reaching the final fill height of $H_{e}=5 \mathrm{~m}$. While $H_{r}$ is a measure of the first instance of column cracking, lower values of $H_{r} / H_{e}$ imply that cracking initiates earlier during the staged filling sequence and that a greater number of elements cracked at the final embankment height. For reference, $H_{r} / H_{e}$ from the undrained numerical demonstration earlier (Figure 6) was 0.55, where fracturing was predicted in columns that extended beneath the crest of the slope. 
Figure 9 illustrates the predicted normalized fill height of rupture $\left(H_{r} / H_{e}\right)$ as a function of crust thickness $\left(H_{1} / H_{e}\right.$ also indicated) when depth to the bearing layer was maintained at $10 \mathrm{~m}$. All else being equal (crust thickness, soft soil type, and drainage condition), lower area replacement ratios resulted in a lower fill height associated with column rupture (Figure 9). Normalized maximum lateral displacements at the embankment toe at the final fill height of $5 \mathrm{~m}$ are also shown (contours in Figure 9). Nearly all undrained simulations result in tensile rupture of some columns prior to the final fill height. Many cases where fracturing was predicted correspond to deformations less than $0.6 \%$, which was typical for high-modulus columns based on documented observations from case histories (Figure 4).

For the same crust thickness and area replacement, lower lateral displacements at the toe and higher values of $H_{r} / H_{e}$ were observed for drained conditions; though there were several combinations of soft soil type, area replacement, and crust thickness where tensile rupture was predicted for the drained condition. It was observed that the lowest area replacement ( $\alpha=3.1 \%$ ) was associated with relatively low values of $H_{r} / H_{e}$ for drained conditions when softer soils SS1 and SS2 were considered (Figure 9a and b), which also coincided with relatively low normalized displacements for several cases (i.e. crust thicknesses). For reference, drained cases where $\alpha=3.1 \%$, and where relatively low normalized deformations were predicted (less than $\sim 0.6 \%$ ) with softest soils SS1 and SS2, cracking occurred the interface of the crust and soft soil in columns that extended back to, or beyond, the crest of the slope. Thus, a signfificant degree of column fracturing at shallow depths can accompany typical performance (i.e. lateral spreading). 


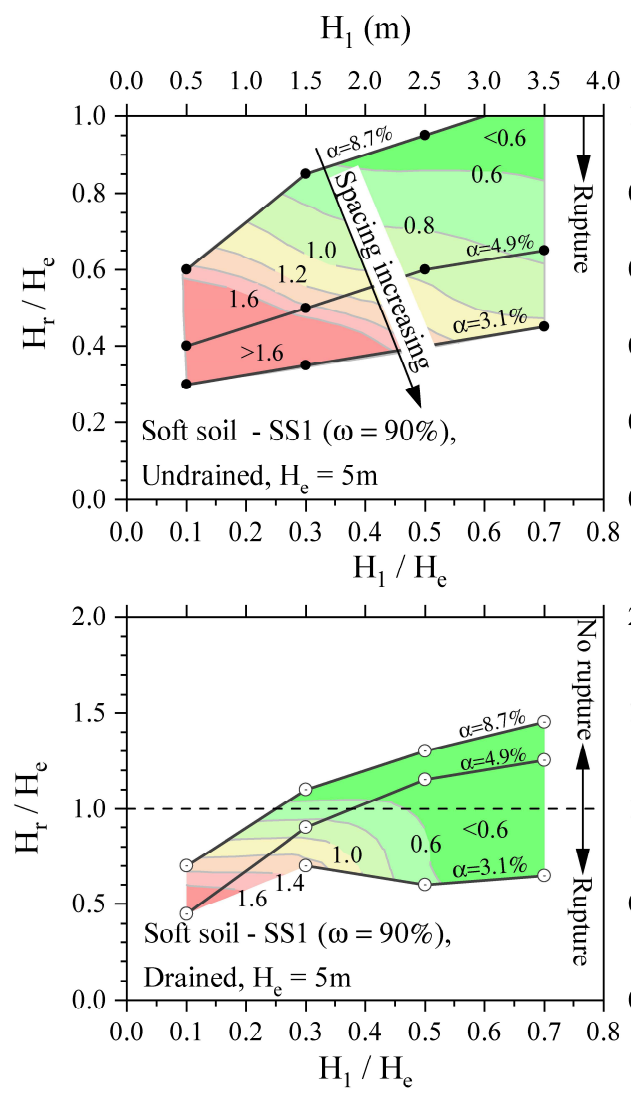

(a)

Normalized defomations at $\mathrm{H}_{\mathrm{e}}=5 \mathrm{~m}$ :

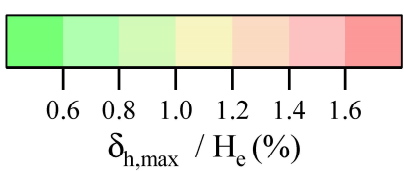

$\mathrm{H}_{1}(\mathrm{~m})$

$\mathrm{H}_{1}(\mathrm{~m})$
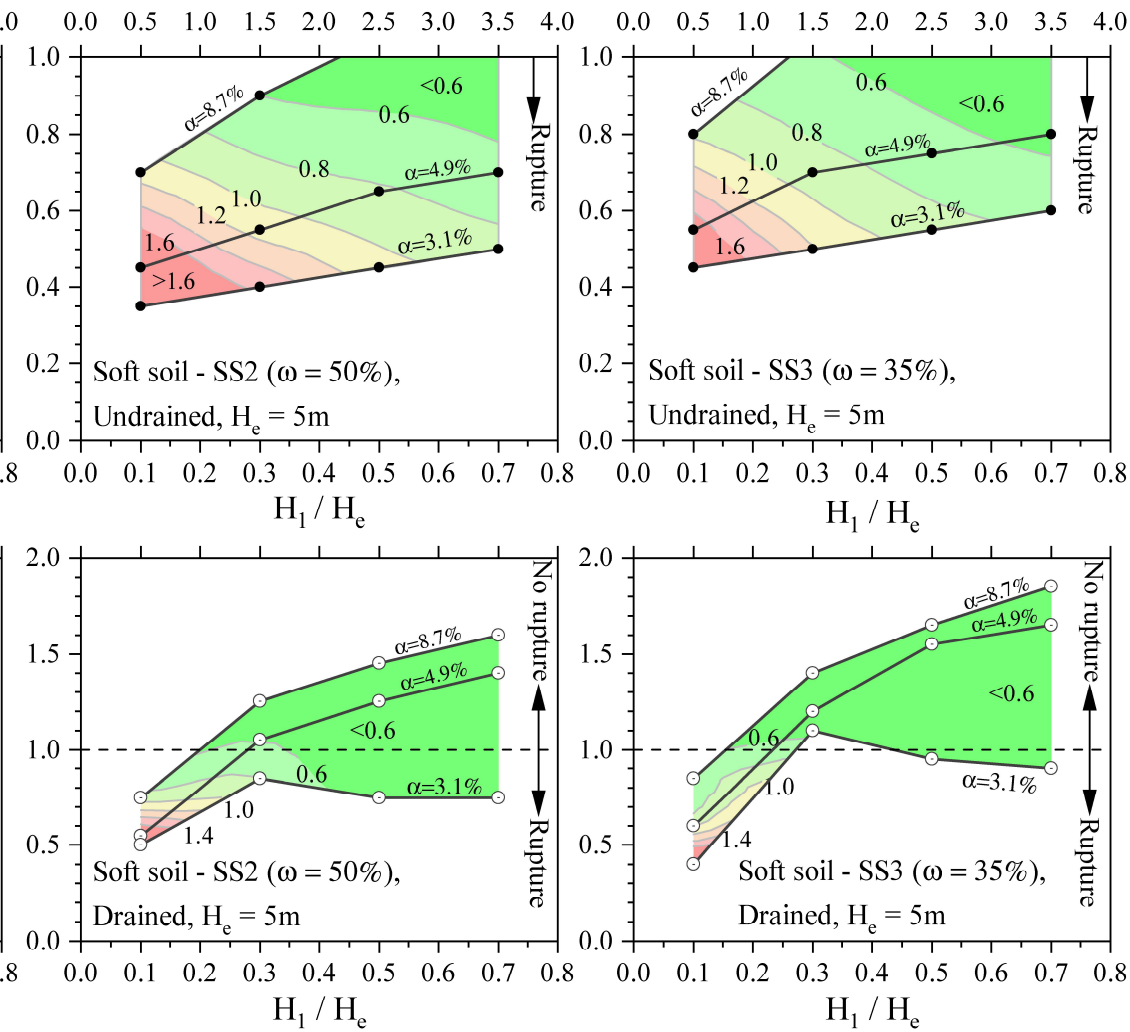

(b)

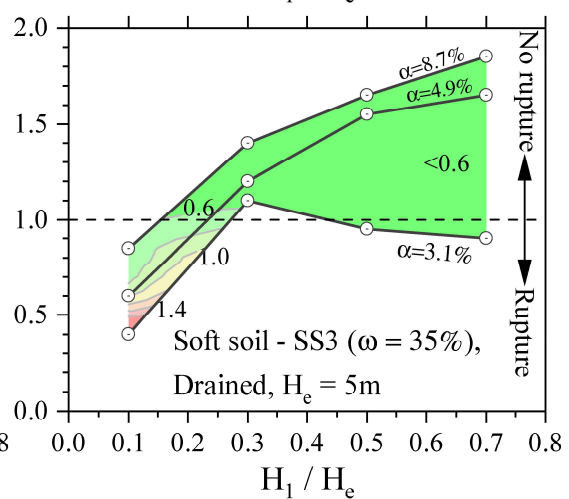

(c)

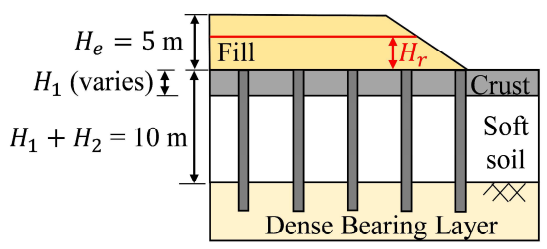

Figure 9. Comparison of the normalized height of rupture vs. normalized crust thickness when depth to the bearing layer is maintained at $10 \mathrm{~m}$. Computed results are shown for undrained (top row) and drained (bottom row) conditions when the soft soil thickness $\left(H_{2}\right)$ is comprised of: a.) SS1; b.) SS2; c.) SS3. Contours indicate the interpolated maximum normalized lateral displacements one column spacing beyond the toe at the final fill height $\left(H_{e}=5 \mathrm{~m}\right)$ for different area replacement ratios.

Figure 10 is identical to Figure 9, but for the second soil profile, where thickness of the crust was maintained at $H_{1}=1.5 \mathrm{~m}$ and thickness of the soft soil and depth to the bearing layer was varied (relevant comparison is for $H_{1} / H_{e}=0.3$ in Figure 9). Decreasing the thickness of the soft soil $\left(H_{2}\right)$ and depth to the bearing layer decreases the effective column length and introduces more curvature in the element. Thus, as thickness of the soft soil decreased, the normalized height of rupture decreased as the soft soil thickness and depth to the bearing layer decreased; i.e. lower fill heights and smaller displacements were required to cause tensile rupture in the embedded columns. For drained cases, although $H_{r} / H_{e}$ decreased with 
decreasing soft soil thickness, this did not result in a greater amount of lateral spreading or constitute more unfavorable subsurface conditions from a basal stability perspective (elaborated on more later).
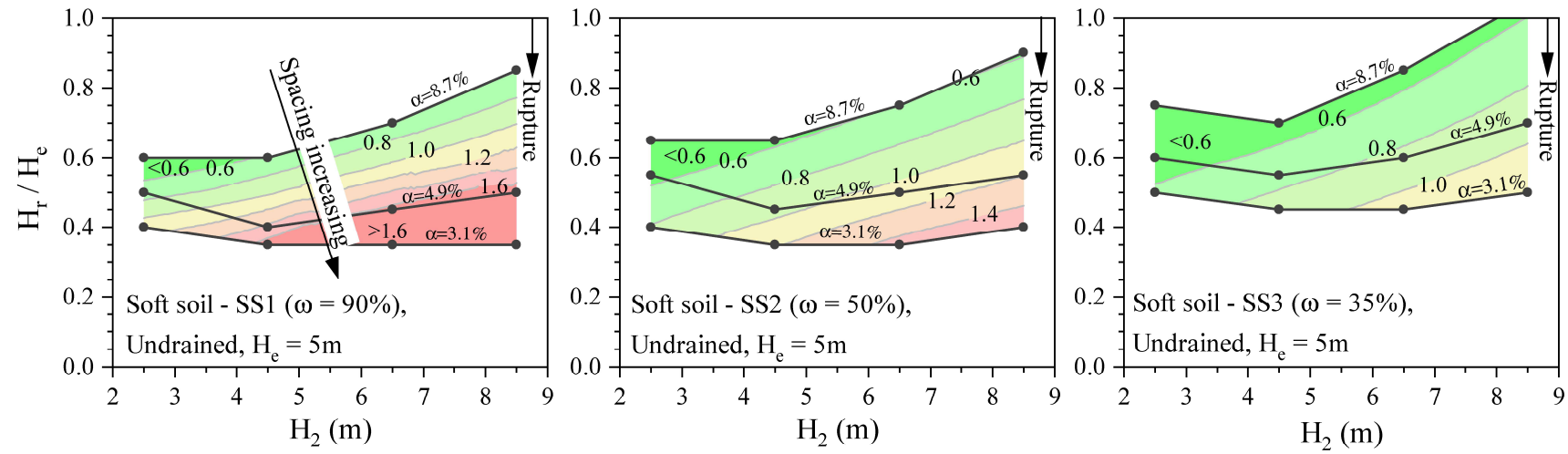

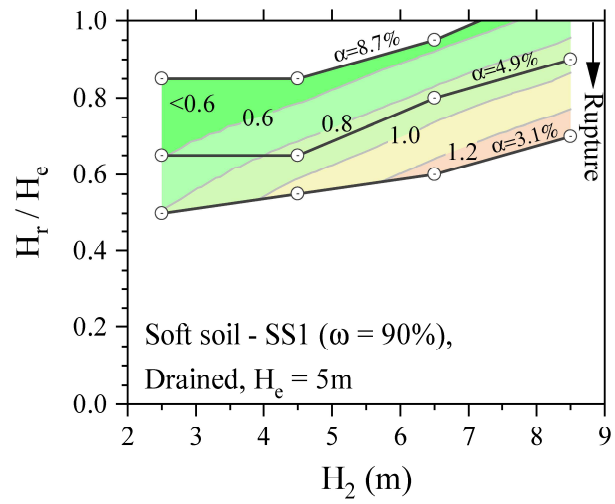

(a)

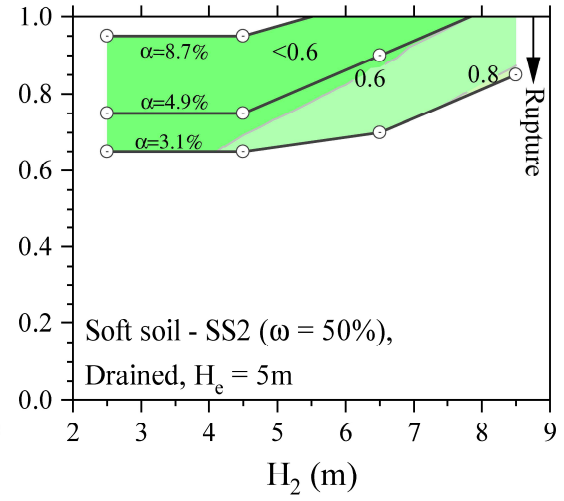

(b)

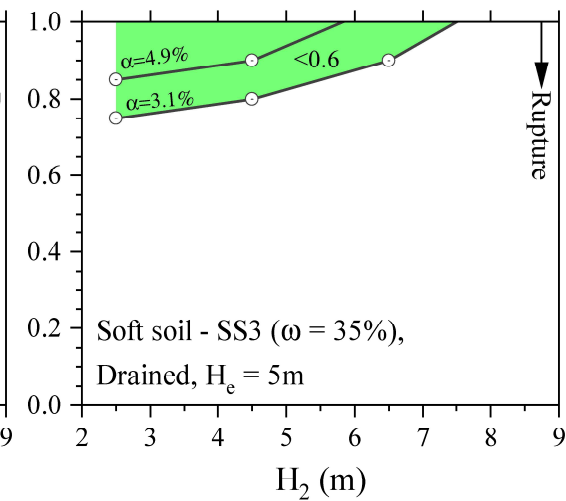

Normalized deformations at $\mathrm{H}_{\mathrm{e}}=5 \mathrm{~m}$ :

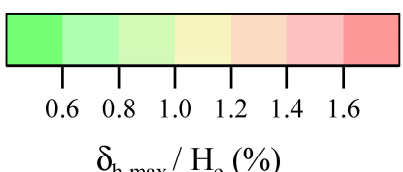

Drainage condition:

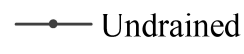

$\longrightarrow$ Drained

(c)

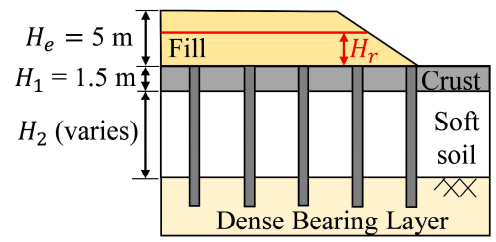

Figure 10. Comparison of the normalized height of rupture vs. thickness of the soft soil $\left(H_{2}\right)$ when $H_{1}=1.5 \mathrm{~m}$ for undrained (top row) and drained (bottom row) conditions when the soft soil thickness $\left(H_{2}\right)$ is comprised of: a.) SS1; b.) SS2; c.) SS3. Contours indicate the interpolated maximum normalized lateral displacements one column spacing beyond the toe at the final fill height $\left(H_{e}=5 \mathrm{~m}\right)$ for different area replacement ratios

\section{Comparison with Field Observations}

Figure 11 summarizes the computed maximum normalized lateral displacements at the toe as a function of normalized crust thicknesses when depth to the bearing layer was maintained at $10 \mathrm{~m}$. The range in computed deformations for different area replacement ratios for both drained (dark grey shading) and undrained (light grey shading) conditions are indicated. Comparisons were also made with observations (black symbols) from the case history inventory where high-modulus columns extended to a stiff bearing layer (non-floating systems). 
Observations from the case histories were in better agreement with drained analyses and indicates that excess pore water pressure generation is limited during CSE construction. Aside from load transfer at the column head, the magnitude of stress imposed on softer foundation soils at depth is curbed by "hang-up" effects due to soil-column interface friction (i.e. downdrag) and subsurface load transfer (Gallant et al., 2018, 2020; Liu et al., 2007; Sloan et al., 2019). Though the rate of filling is typically accelerated with column-support, stress changes in the foundation materials are concentrated at shallower depths, which significantly reduces the effective drainage distance and facilitates a partially (or nearly) drained condition during filling. This is supported by several studies that report limited consolidation settlement and/or measured excess pore water pressure in soft soils at the end of construction (e.g. Briançon \& Simon, 2012; Gallant et al., 2020; Liu et al., 2007, 2015, p. 2, 2009, 2012; Yapage et al., 2014)

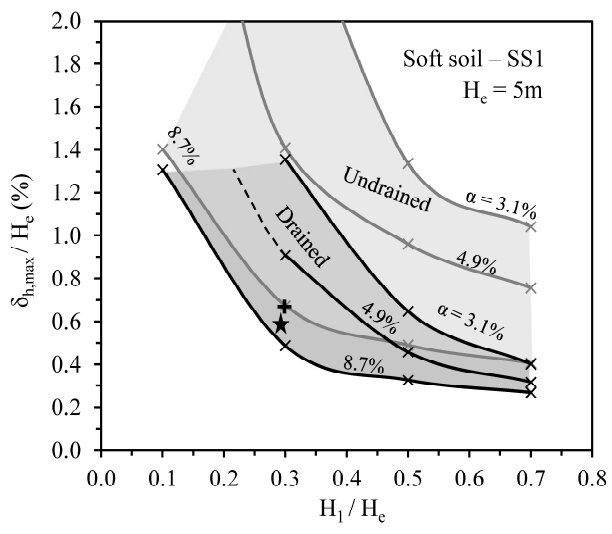

(a)

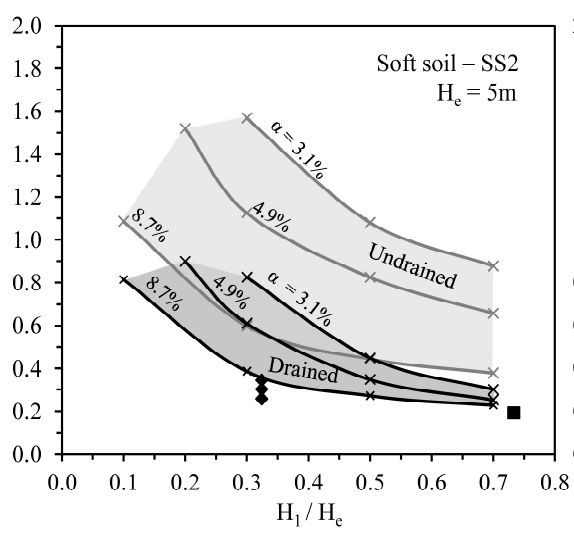

(b)

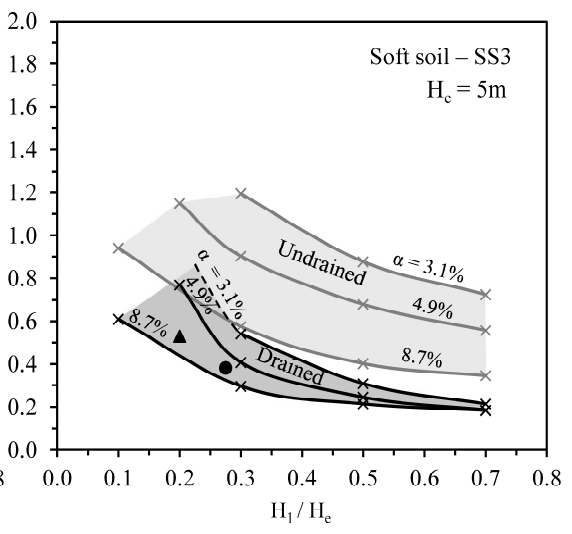

(c)

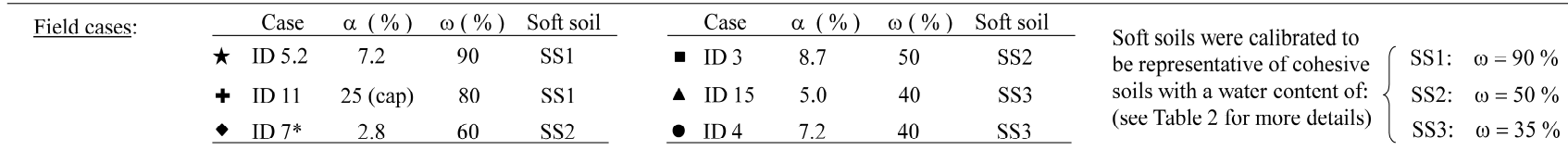

$* \mathrm{H}_{2}$ was atypical and equal to $1 \mathrm{~m}$

Figure 11. Computed maximum normalized lateral deformations one column spacing beyond the toe vs. normalized crust thickness when depth to the bearing layer is maintained at $10 \mathrm{~m}$ for soft soil conditions: (a) SS1; (b) SS2; (c) SS3. Deformations for $H_{e}=5 \mathbf{m}$ are shown for all cases. Comparison is made with observations (black symbols) for cases where high-modulus columns extended to a stiff bearing layer

Similar to the field observations (Figure 4c), Figure 11 illustrates that there was a threshold normalized crust thickness, below which predicted deformations began increasing significantly as normalized thickness of the crust decreased. This trend is attributed to a relatively high degree of mobilized passive resistance and relatively low factor of safety regarding loss of confinement at the toe, reemphasizing the crust's importance with regards to toe confinement and basal stability. For drained conditions, this increase was predicted at normalized lateral deformations between approximately $0.4-0.6 \%$ depending on soft soil type and area replacement. For undrained conditions, this was predicted at larger deformations (0.6-1.1\%). The increase in deformations for lower crust thicknesses was less pronounced for soft soils 
SS2 and SS3 (Figure 11b,c), as the relative difference in stiffness between the soft soil and crust was smaller.

\section{Factor of Safety}

Though observations from the case-history inventory provided some precedent for the degree of acceptable lateral spreading, this must be linked to a factor of safety against basal instability, as maintenance of intended vertical load transfer into fractured columns rely on confinement provided by the foundation soils at the toe. Simplified limit equilibrium (LE) methods recommended to address lateral spreading and deeper-seated global instabilities for CSEs (British-Standard, 2010; China-MOT, 2015; Japan Road Association, 2012; Schaefer et al., 2017) neglect the redistribution of stress in the embankment fill and foundation soils (Huang et al., 2020), as well as the increased stress in the columns and corresponding decrease in applied stress on the foundations materials due to arching and downdrag. Moreover, LE global stability analyses intended to evaluate the factor of safety for potential slip surfaces that extend through the columns often adopt a "composite" soil strength that considers the shear resistance of the columns (Schaefer et al., 2017). This implicitly assumes the columns would rupture in shear, though the lateral resistance of unreinforced high-modulus columns is limited by the available tensile capacity and bending resistance, not the shear strength of concrete. Limit equilibrium "lateral spreading" analyses are akin to sliding checks for earth retention systems, which neglect a.) potential strain discontinuities and slip surfaces that develop at the interface of a crust and soft soil and b.) the influence (and benefits) of crust thickness in providing restraint at the toe. Therefore, an approach to address factors of safety that reflect the mode of failure at the toe is proposed to overcome limitations of these existing methodologieswhich were originally intended for, or modified from, approaches to check stability for other geotechnical systems.

Because the crust is stronger than the underlying soft clay, the lateral thrust applied by the embankment must first overcome the available passive resistance in this material. Figure 12 illustrates the shear strains, displacements (Figure 12a), and passive failure block (Figure 12b) formed near the toe when lateral spreading is uncontrolled. When columns extend to the toe, the passive block in the crust generally developed in three stages. First, an initial rupture plane forms in the crust (noted as 1 in Figure 12b) due to the lateral thrust imposed by the embankment. This instigates sliding of the crust atop the softer clay, indicated by the relatively large shear strains shown in the soft clay in Figure 12a. However, there is some principal stress rotation in the crust adjacent to the embankment, which results in the first rupture plane being inclined more steeply than the theoretical angle of a passive wedge subjected to horizontal stress 
changes only. Thus, the crust is able to continue transferring load horizontally until a second rupture plane develops at a shallower angle (2 in Figure 12b), creating a block that is "squeezed out" (see displacement vectors within the failure block in Figure 12a). The second rupture plane is inclined at the theoretic angle of a passive wedge in pure extension (i.e. $\pi / 4-\phi^{\prime} / 2$ ) as there is no principal stress rotation in the crust at this location.

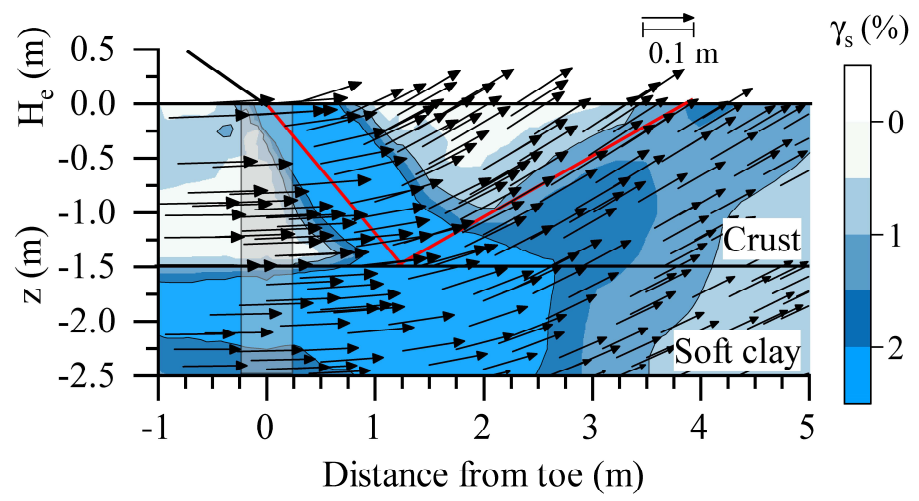

(a)

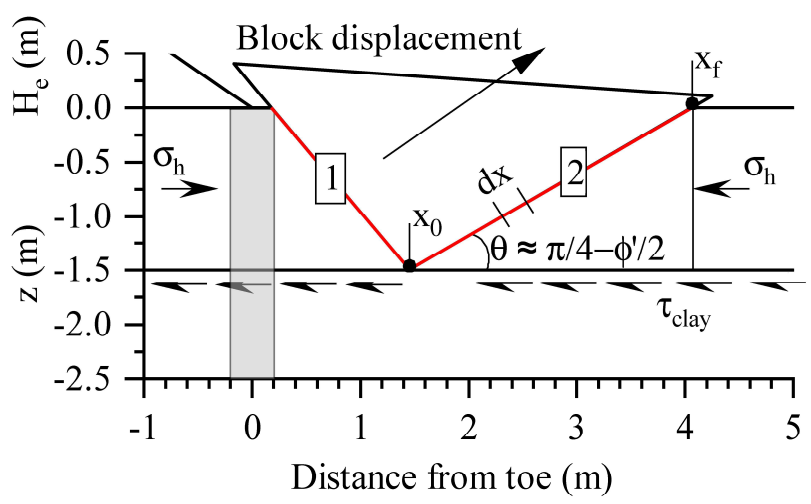

(b)

Figure 12. Representative shear strains, displacements, and passive wedge formation at the toe: (a) shear strains and displacement vectors at the toe indicating two rupture planes in the crust (red lines); (b) conceptual illustration of passive wedge formation at the toe. The case shown is for $H_{1}=1.5 \mathrm{~m}$ for undrained conditions

Figure 13 compares the computed lateral deformations, embankment height, and normalized displacements associated with the relative mobilized shear stress along the second rupture plane in the crust, defined as:

$$
\tau_{\text {rel }}=\int_{x=x_{0}}^{x=x_{f}} \frac{\tau_{\text {mob }}}{\tau_{\max }} d x
$$

where $\tau_{m o b}$ and $\tau_{\text {max }}$ are the mobilized shear stress and available shear strength in the crust, respectively; $\tau_{\max }=p^{\prime} \sin \phi^{\prime}+c^{\prime} \cos \phi^{\prime}$, where $p^{\prime}=\left({\sigma^{\prime}}_{1}+\sigma_{3}^{\prime}\right) / 2$ is the mean normal effective stress. Therefore, $\tau_{r e l}$ is based on current effective stress-levels in the crust, which were extracted from the 3D FEA at each stage (fill height) during a simulation. The start and end of the second rupture surface are indicated by $x_{o}$ and $x_{f}$ in Figure $12 \mathrm{~b}$. For the drained case, $x_{o}$ was aligned with the toe.

Figure 13 compares the relative shear strength with lateral displacements, embankment height, and normalized lateral toe displacements for several crust thicknesses for both undrained and drained conditions. It can be seen that displacements are uncontrolled and the toe is no longer confined once $\tau_{\text {rel }}$ 
approaches one. Thus, it is reasonable to define the factor of safety for loss of toe confinement as the inverse of the relative mobilized shear strength $\left(\mathrm{FS}=1 / \tau_{\text {rel }}\right)$, which is indicated on the secondary axis in Figure 13c. This definition of factor of safety is proposed as it reflects the mode of failure and accounts for the influence of crust-thickness with regards to lateral spreading and confinement provided by foundation soils at the toe. Displacements and embankment heights associated with the same factor of safety can differ for different crust thicknesses. Therefore, displacement-based criteria (e.g. precedent based on case histories) alone are discouraged to justify adequate toe confinement.
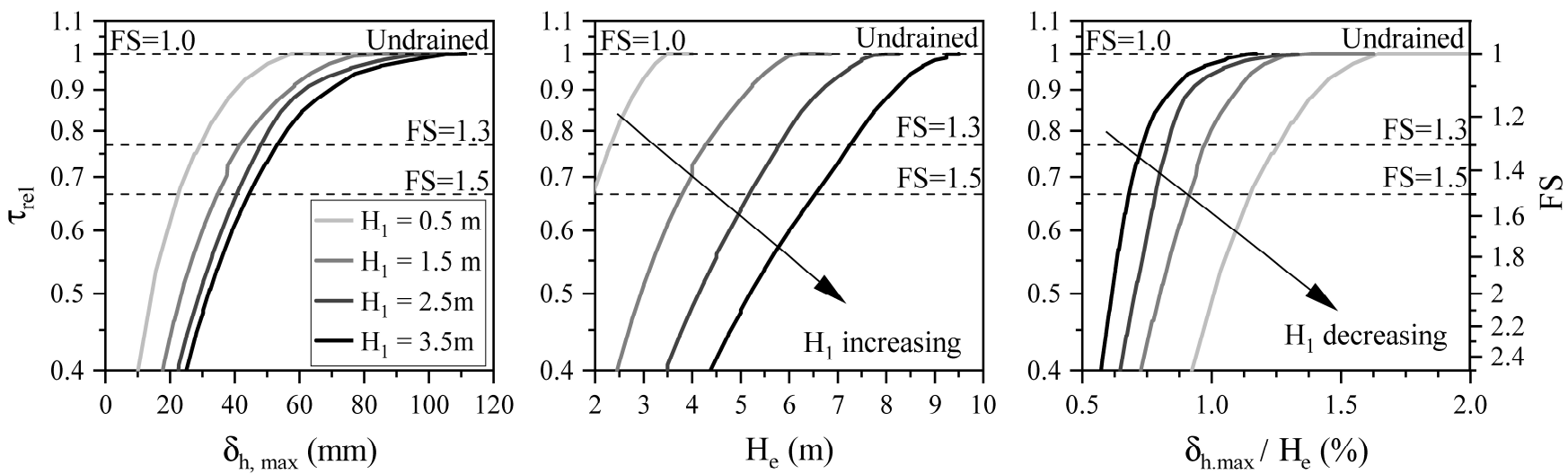

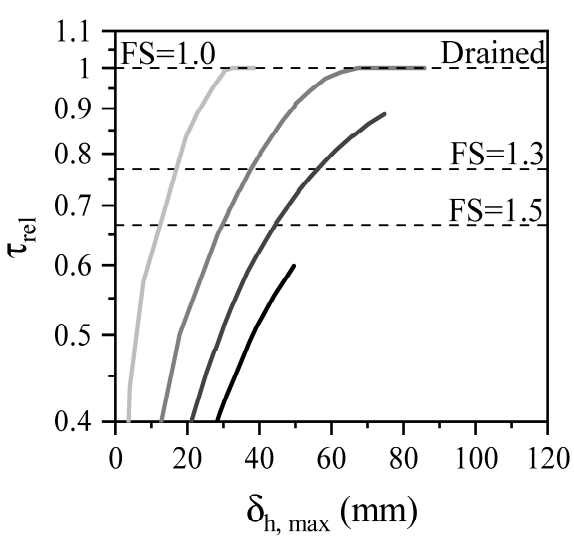

(a)

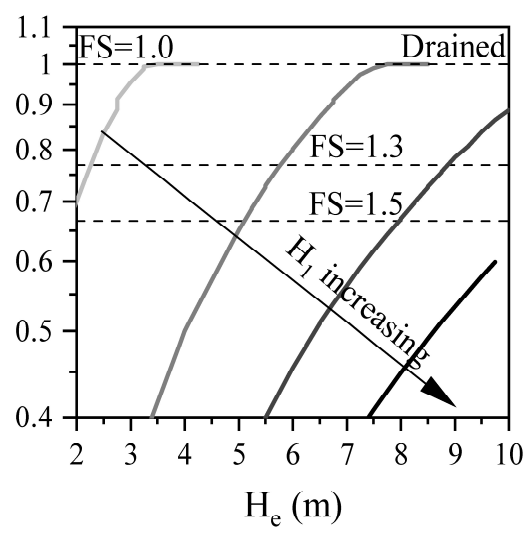

(b)

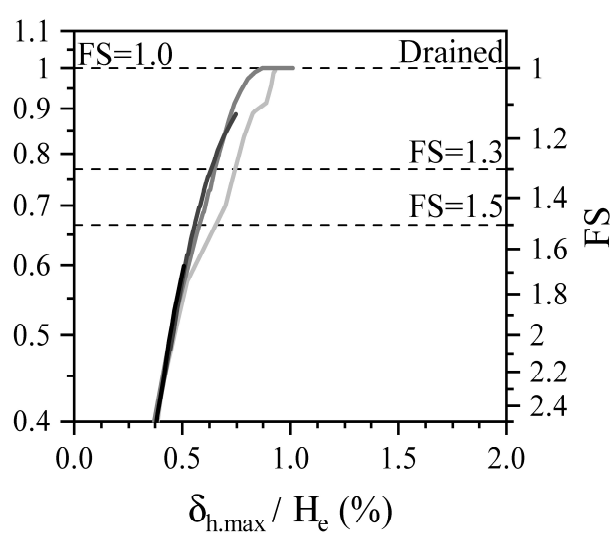

(c)

Figure 13. Computed relative shear stress, $\tau_{\text {rel }}$, compared with: (a) maximum lateral toe deformations; (b) embankment height; (c) normalized maximum lateral toe deformations. Comparisons are shown for undrained (top row) and drained (bottom row) conditions for $H_{1}+H_{2}=10 \mathrm{~m}$, soft soil SS2, and $\alpha=4.9 \%$.

Figure 14 compares the normalized height of column rupture and corresponding factors of safety (contours) computed at the final embankment height of $5 \mathrm{~m}$ when depth to the bearing layer was maintained at $10 \mathrm{~m}$ and crust thickness was varied. Lower factors of safety were associated with undrained conditions and lower area replacement, as expected. However, generally accepted long-term factors of safety for lateral spreacing (FS $>1.5$ ) were achieved when column fracturing was predicted for several 
cases. Higher crust thicknesses were needed to achieve factors of safety greater than 1.5 for undrained versus drained conditions.

Figure 15 compares the normalized height of rupture and corresponding factors of safety when soft soil thickness was varied and a crust thickness of $1.5 \mathrm{~m}$ was maintained. Though undrained conditions result in unacceptable low factors of safety, many drained scenarios are associated with factors of safety near or greater than 1.5. Additionally, as $H_{r} / H_{e}$ decreases, lower factors of safety were not predicted. In fact, for drained cases, as $\mathrm{H}_{2}$ decreases the factor of safety either remains constant or increases marginally as $H_{r} / H_{e}$ and soft soil thickness decrease.

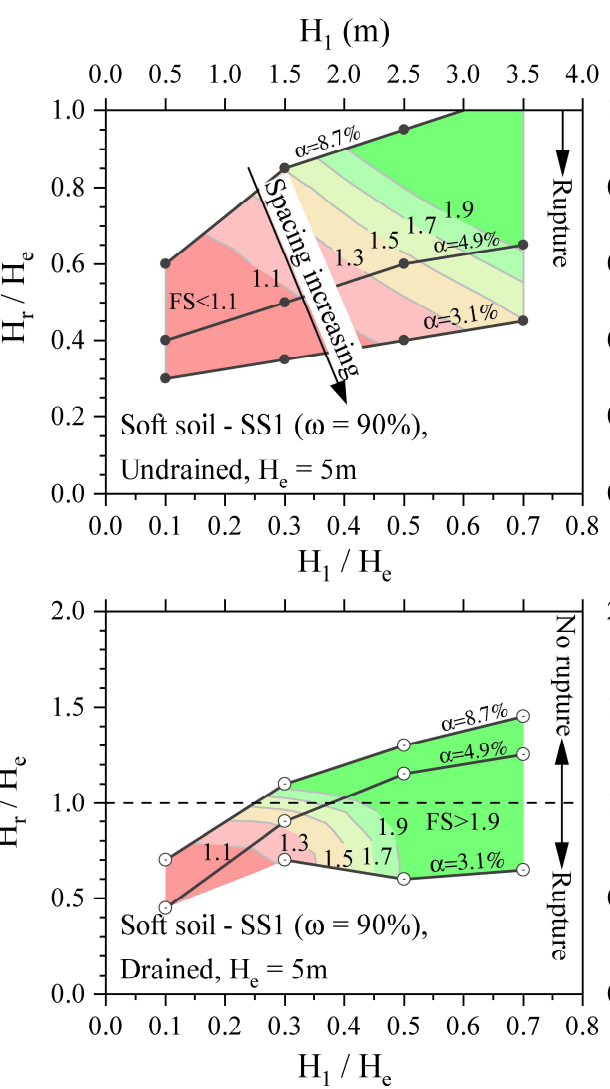

(a)

Factors of Safety at $\mathrm{H}_{\mathrm{e}}=5 \mathrm{~m}$ :

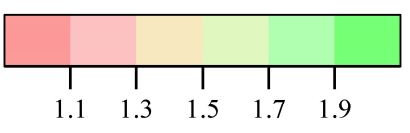

FS
$\mathrm{H}_{1}(\mathrm{~m})$

$\mathrm{H}_{1}(\mathrm{~m})$
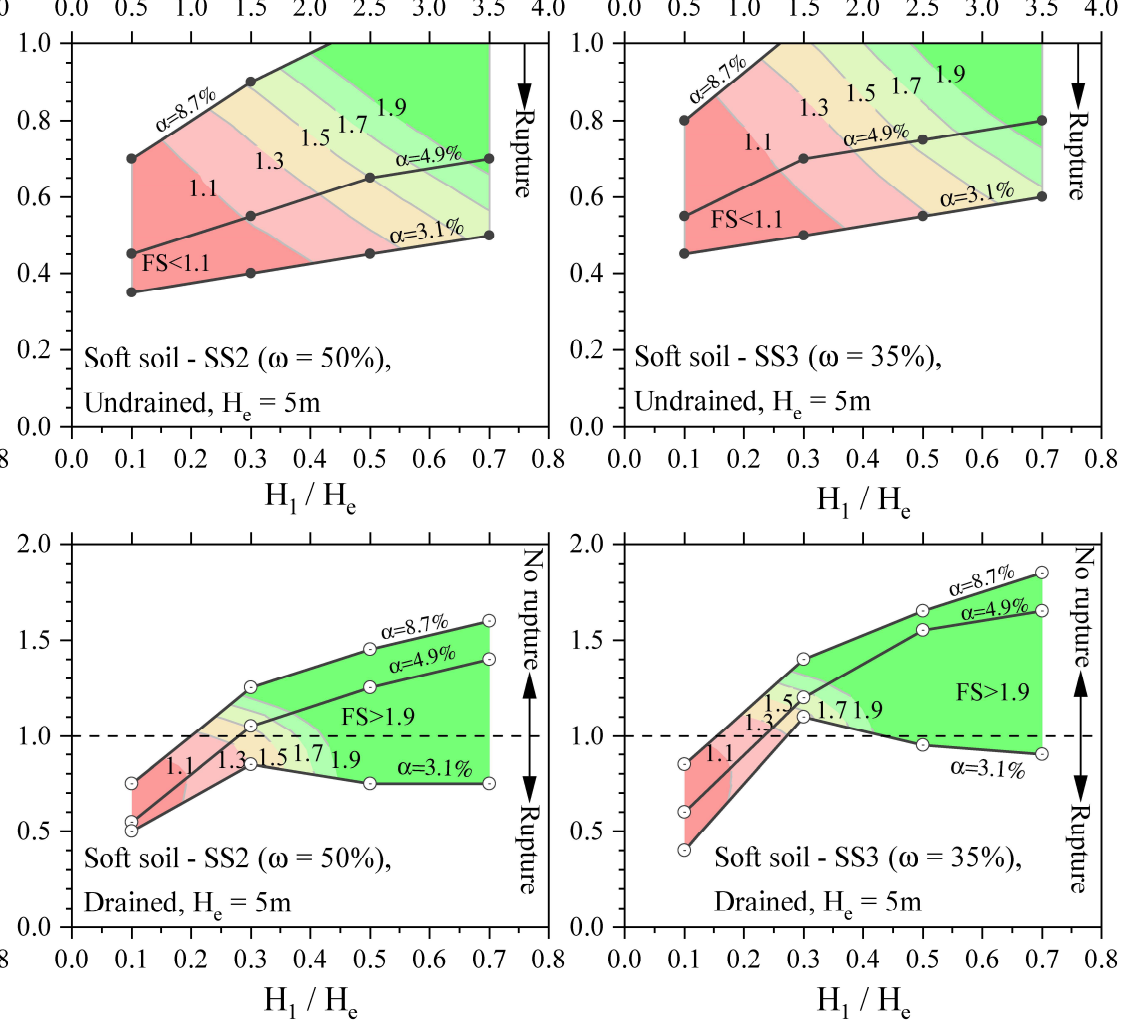

(b)

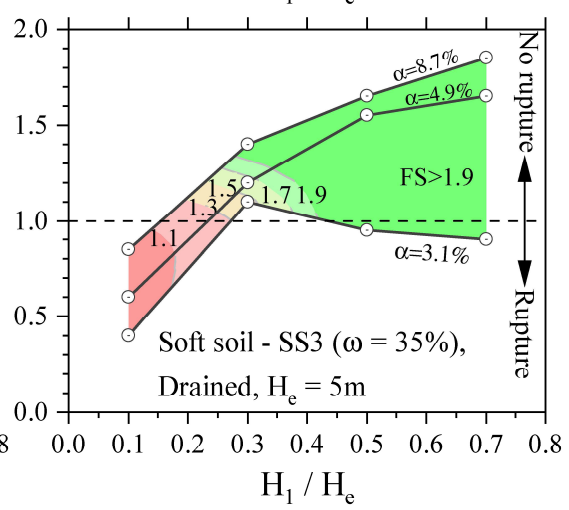

(c)

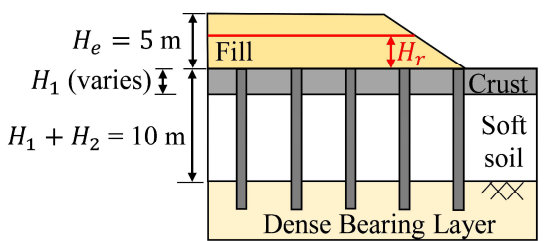

Figure 14. Comparison of the normalized height of rupture vs. normalized crust thickness when depth to the bearing layer is maintained at $10 \mathrm{~m}$. Computed results are shown for undrained (top row) and drained (bottom row) conditions and for different area replacement ratios when the soft soil thickness $\left(H_{2}\right)$ is comprised of: (a) SS1; (b) SS2; (c) SS3. 
Contours indicate the interpolated factor of safety at the final fill height $\left(H_{e}=5 \mathrm{~m}\right)$ for different area replacement ratios
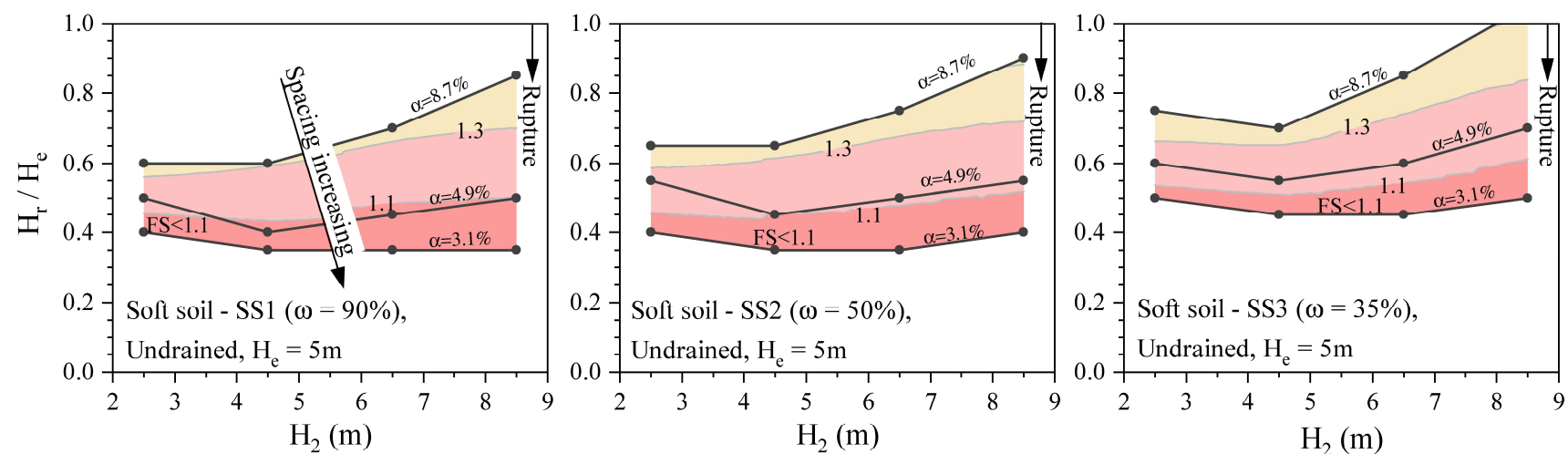

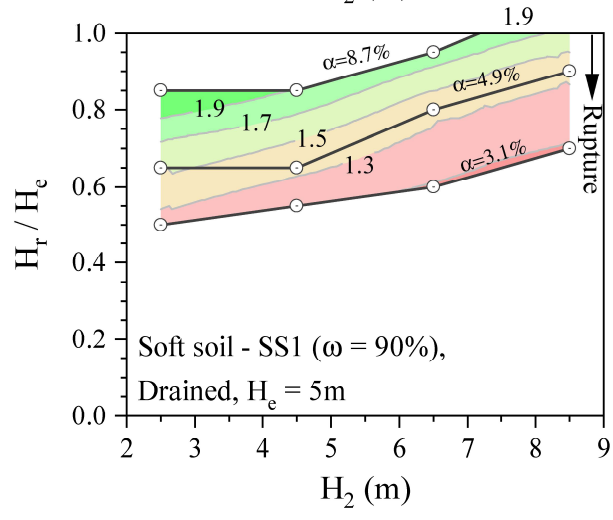

(a)

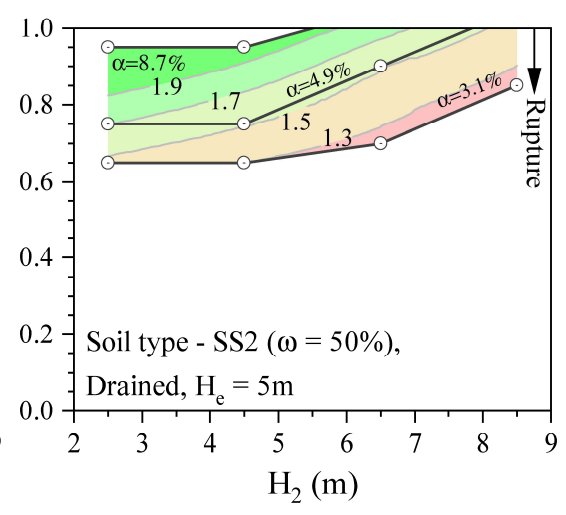

(b)

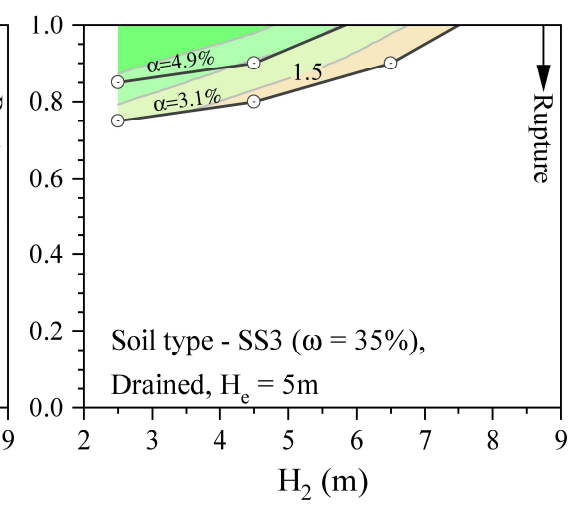

$\underline{\text { Factors of safety at }} \mathrm{H}_{\mathrm{e}}=5 \mathrm{~m}$ :

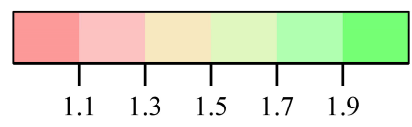

FS
Drainage condition:

$\longrightarrow$ Undrained

— Drained (c)

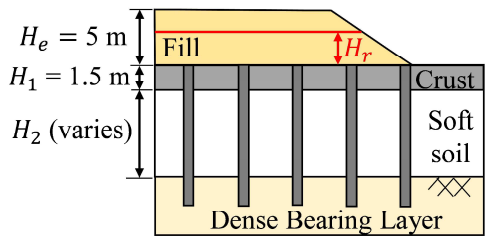

Figure 15. Comparison of the normalized height of rupture vs. thickness of the soft soil $\left(H_{2}\right)$ when $H_{1}=1.5 \mathrm{~m}$ for undrained (top row) and drained (bottom row) conditions and for different area replacement ratios when the soft soil is comprised of: (a) SS1; (b) SS2; (c) SS3. Contours indicate the interpolated factor of safety at the final fill height $\left(H_{e}=\right.$ $5 \mathrm{~m})$ for different area replacement ratios

Figure 16 summarizes the factors of safety computed for all numerical simulations and their corresponding normalized displacements at a fill height of $5 \mathrm{~m}$. Generally accepted long-term and temporary factors of safety of 1.5 and 1.3 are also indicated. The maximum normalized lateral displacements corresponding to factors of safety greater than 1.5 ranged between $0.4-0.9 \%$ and $0.2-0.6 \%$ for undrained and drained conditions, respectively. Notably, the range of deformations where factors of safety were greater than 1.5 align with documented observations from the case histories for high-modulus columns, and there were many cases where column fracturing was predicted $\left(\mathrm{H}_{\mathrm{r}} / \mathrm{H}_{\mathrm{e}}<1\right)$ prior to reaching the final embankment height (closed symbols in Figure 16) 
However, the range of deformations corresponding to factors of safety less than 1.3 overlapped with deformations associated with higher factors of safety, but different conditions, in some cases. This overlap occured because the magnitude of lateral spreading associated with full mobilization of passive resistance in the crust decreases when soft soil thickness or the relative difference in stiffness between the soft soil and crust decreases. The soft soil does carry and resist some of the lateral load imposed by the embankment on the foundation soils and contributes to the magnitude of lateral spreading. The influence of decreasing soft soil thickness is reflected by decreasing normalized displacements for "star" symbols with the same area replacement (indicated by symbol color in Figure 16). When the relative difference in stiffness between the crust and soft soil is lower, smaller deformations will be associated with full mobilization of passive resistance in the crust, which was used to define the factor of safety. For example, when $H_{1}=0.5$ $\mathrm{m}$ and $\alpha=8.7 \%$ (brown squares), the factor of safety was close to 1 for all drained cases (see Figure 16b) and deformations were as low as $0.6 \%$ for the stiffest soft soil type (SS3). Higher deformations for $H_{1}=$ $0.5 \mathrm{~m}$ and $\alpha=8.7 \%$ were predicted for SS1 and SS2 (0.8 and 1.3\%). Thus, displacement-based criteria (or precedent from previous projects) should not solely be relied on as an indicator of stability for CSEs supported on high-modulus columns without geosynthetic reinforcement. The area replacement, fill height, and subsurface conditions, including relative thickness and stiffness between the crust and soft soil, must be considered together when linking factor of safety for basal stability at the toe to deformations observed in the field. 


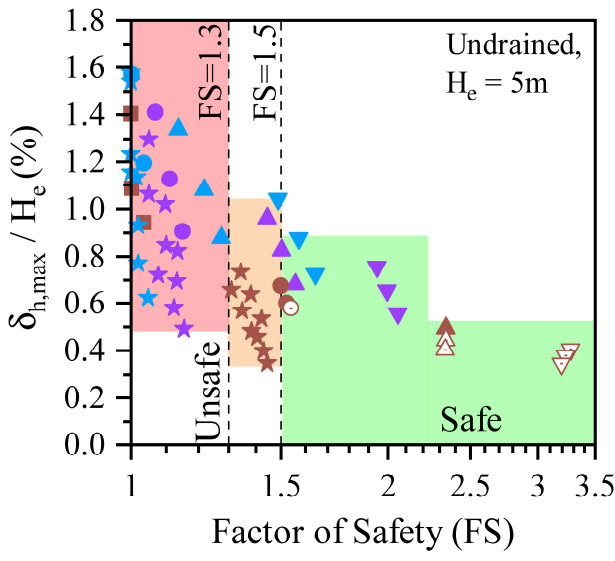

(a)

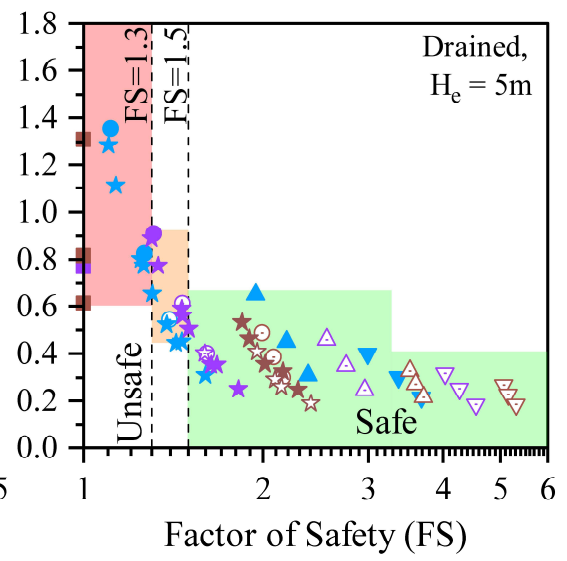

(b)

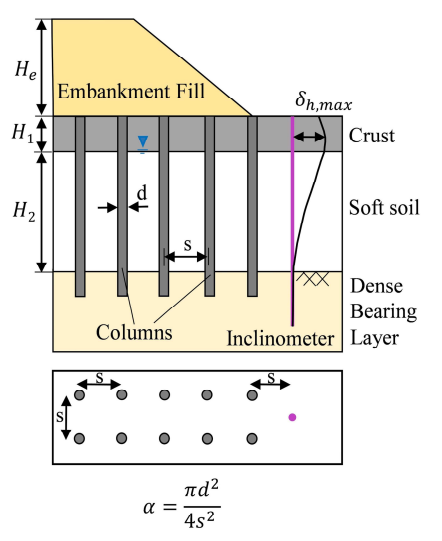

Legend:

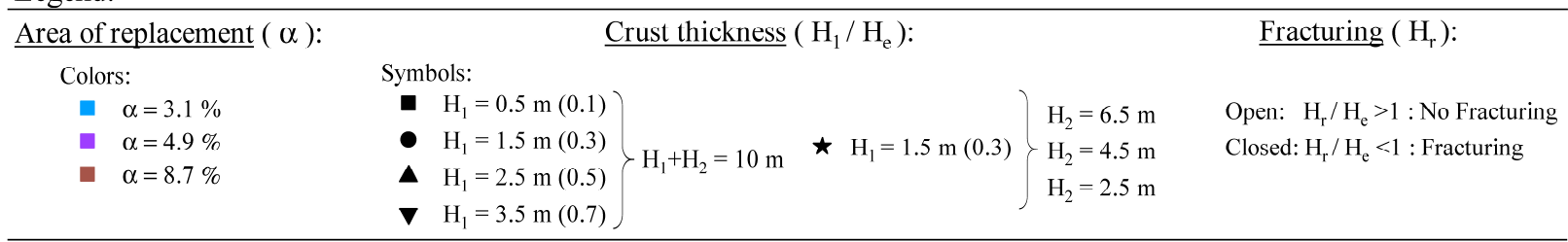

Figure 16. Summary of computed factors of safety at $H_{e}=5 \mathrm{~m}$ and the corresponding normalized lateral displacements for all numerical simulations presented in the parametric study: (a) undrained and (b) drained conditions. Symbol colors indicate area replacement ratio, symbol shapes indicate crust thickness, and closed symbols indicate column fracturing was predicted below $H_{e}=5 \mathrm{~m}$

From a cost perspective, it would be desirable to decrease area replacement when an acceptable degree of lateral spreading and adequate factors of safety are achieved. There were many scenarios where column fracturing was predicted and a factor of safety of at least 1.5 was achieved without geosynthetic reinforcement, which demonstrated that adequate stability can accompany scenarios where column fracturing occurs. For undrained cases, significantly fewer cases resulted in factors of safety greater than 1.5 than for the drained limit state (Figure 16). However, observations from the case history history inventory were in better agreement with normalized lateral deformations for drained predictions (Figure 11). Thus, the drainage condition during CSE construction - which is influenced by the rate of filling, depth to the water table, presence of sand lenses, crust thickness, and hang-up effects due to downdragis often better approximated by the drained limit state when using high-modulus elements that extend to a stiff bearing layer (i.e. not floating). However, blind use of this unconservative assumption would be imprudent. Similar analyses to the ones performed here can be performed by evaluating the pore pressure generation (and dissipation) based on the rate of construction. Additionally, a field monitoring program or test embankment may be warranted to justify the validity of a drained or partially drained assumption for large projects (e.g. highway embankments). Where savings provided by optimizing area replacement could be substantial, a field monitoring program could be accompanied by an adaptive management 
approach during construction, where lower area replacements may be justified at embankment sections not yet constructed depending on observed performance at nearby locations or a test embankment.

The simulations presented in this study considered CSE systems where the columns extended to the toe of the embankment, and development of a passive failure block (i.e. Figure 12) was identified for all cases. However, indentification of critical failure modes, rupture planes in the crust, and extraction of moblized shear stresses from 3D finite element analyses are cumbersome and time consuming. There remains a need for development of simplified methodologies that reflect the mode of failure in the crust and that overcome the limitations of existing limit equilibrium methods (previously discussed). This should be the subject of future work so that the benefits associated with thickness and restraint provided by a surficial layer of crust, which often exists, may be easily accounted for in design.

\section{Summary and Conclusions}

It has been disputed in industry if unreinforced high-modulus columns supporting CSEs should be allowed to tolerate some degree of crack development, as the cessation of bending resistance on lateral stability of CSE systems remains a salient concern. The objectives of this study were to i.) elucidate the influence of column fracturing on lateral spreading and performance and ii.) to address whether adequate confinement and factors of safety can be achieved when fracturing occurs. A collective assessment of available performance data established some precedent for the magnitude of lateral spreading typically observed and provided context regarding the influence of a stiff surficial crust on performance. A 3D finite element study of hypothetical embankments, which considered the cessation of column bending resistance due to tensile rupture at discrete crack locations, was conducted to achieve the aforementioned objectives. A methodology to assess the factor of safety was proposed to reflect the anticipated mode of failure at the embankment toe and to account for the benefits of crust thickness. Based on the examination of documented lateral spreading from case histories and the numerical analyses:

- The maximum normalized lateral deformations $\left(\delta_{h, \max } / H_{e}\right)$ documented near the toe of columnsupported systems are typically less than $1 \%$, and were less than $0.6 \%$ for embankments supported on high-modulus columns that extended to a substantially stiffer bearing layer (i.e. not floating). The magnitude of lateral spreading decreases with increasing thickness of a stiff surficial crust, which influences the distribution of lateral movements and provides appreciable resistance at the embankment toe. 
- Lateral spreading that occurs during filling causes column fracturing to generally progress from perimeter elements to trailing columns behind the toe. A numerical comparison of lateral spreading imposed by an embankment supported on fractured and unfractured columns revealed that the cessation of column bending resistance at discrete crack locations has a negligible influence on performance (lateral spreading and load transfer). Thus, while column fracturing is a consequence of lateral spreading, it does not exacerbate spreading and column bending resistance does not appreciably influence stresses imparted on foundation soils that may trigger instability.

- It was demonstrated that incorporation of geosynthetic-reinforcement in an LTP-which is often included in CSE systems to mitigate lateral instability-does not significantly influence the embankment height or locations where fracturing occurs. Geosynthetic does not engage significantly until lateral spreading has progressed such that passive resistance at the toe of the embankment is nearly fully-mobilized and column fracturing has occurred. Therefore, reliance on mobilization of tensile resistance from geosynthetic-reinforcement to maintain lateral stability is incompatible with a design constraint that precludes fracturing of unreinforced elements.

- Without geosynthetic-reinforcement, a stiff surficial layer of crust becomes a critical component of lateral stability and confinement at the toe. It was demonstrated that uncontrolled lateral spreading accompanies development of a passive block in the crust at the embankment toe and a factor of safety was defined based on the relative degree of mobilized shear strength along a critical rupture plane. Using this definition for factor of safety, it was shown that factors of safety greater than 1.5 can accompany fracturing (even at shallow depths) that extends to columns signficantly behind the toe. This understanding can be used to optimize area replacement to decrease cost and/or justify elimination of steel reinforcement in perimeter columns to increase construction efficiencies.

- Computed normalized lateral deformations at the embankment toe associated with factors of safey greater than 1.5 were $0.9 \%$ and $0.6 \%$ for undrained and drained conditions, respectively. Notably, comparison of computed results with field observations for high-modulus columns indicate that a partially (or nearly) drained condition is likely associated with CSE construction in most instances. However, it would be imprudent to apply the drained limit state indiscriminately in design. A field monitoring program or test embankment may be warranted to justify the validity of this assumption for large projects, where the savings provided by optimizing area replacement could be substantial. A field monitoring program could be accompanied by an adaptive management approach to 
construction, where alternative lower area replacements may be justified at embankment sections not yet constructed depending on observed performance at nearby locations or a test embankment.

In closing, this study demonstrated that there are many situations where column fracturing occurs and a CSE system performs as intended. However, there remains a need for development of simplified design methodologies that reflect the anticipated mode of failure in a stiff crust to overcome the limitations of existing limit equilibrium methods often applied in practice to address lateral spreading. Future work should consider development of simplified methodologies so that the benefits associated with crust thickness are accounted for.

\section{Acknowledgments}

The authors gratefully acknowledge the funding provided for this research by the Deep Foundations Institute's Ground Improvement and Augered Cast-in-Place and Drilled Displacement Pile technical committees for their financial support of this work. Additional support provided by the Transportation Infrastructure Durability Center at University of Maine under grant 69A3551847101 from the U.S. Department of Transportation University Transportation Center Program is also greatly appreciated.

\section{References}

Almeida, M. S., Hosseinpour, I., Riccio, M., \& Alexiew, D. (2015). Behavior of geotextile-encased granular columns supporting test embankment on soft deposit. Journal of Geotechnical and Geoenvironmental Engineering, 141(3), 04014116.

Azzouz, A. S., Krizek, R. J., \& Corotis, R. B. (1976). Regression analysis of soil compressibility. Soils and Foundations, 16(2), 19-29.

Bazant, Z. P., Pfeiffer, P. A., \& others. (1987). Determination of fracture energy from size effect and brittleness number. ACI Materials Journal, 84(6), 463-480.

Benz, T., Vermeer, P., \& Schwab, R. (2009). A small-strain overlay model. International Journal for Numerical and Analytical Methods in Geomechanics, 33(1), 25-44.

Briançon, L., \& Simon, B. (2012). Performance of pile-supported embankment over soft soil: Full-scale experiment. Journal of Geotechnical and Geoenvironmental Engineering, 138(4), 551-561. 
British-Standard. (2010). BS 8006-1: Code of practice for strengthened/reinforced soils and other fills. London.

Broms, B. (2003). Deep soil stabilization: Design and construction of lime and lime/cement columns. Stockholm: Royal Institute of Technology.

Chai, J., Shrestha, S., \& Hino, T. (2019). Failure of an Embankment on Soil-Cement Column-Improved Clay Deposit: Investigation and Analysis. Journal of Geotechnical and Geoenvironmental Engineering, 145(9), 05019006.

Chai, J., Shrestha, S., Hino, T., \& Uchikoshi, T. (2017). Predicting bending failure of CDM columns under embankment loading. Computers and Geotechnics, 91, 169-178.

Chai, J.-C., Shrestha, S., Hino, T., Ding, W.-Q., Kamo, Y., \& Carter, J. (2015). 2D and 3D analyses of an embankment on clay improved by soil-cement columns. Computers and Geotechnics, 68, 28-37.

China-MOT. (2015). Specifications for Design of Highway Subgrades (JTG D30-2015). China Communications Press: Beijing, China.

Clough, G. W. (1990). Construction induced movements of in situ walls. Design and Performance of Earth Retaining Structures, 439-470.

Deb, K., \& Mohapatra, S. R. (2013). Analysis of stone column-supported geosynthetic-reinforced embankments. Applied Mathematical Modelling, 37(5), 2943-2960.

Filz, G. M., Sloan, J. A., McGuire, M. P., Smith, M., \& Collin, J. (2019). Settlement and Vertical Load Transfer in Column-Supported Embankments. Journal of Geotechnical and Geoenvironmental Engineering, 145(10), 04019083.

Gallant, A. P., Shatnawi, E., \& Botero-Lopez, D. (2020). Field Observations and Analysis of the Subgrade Response Beneath GRCS Embankments at the Council Bluffs Interchange System. Journal of Geotechnical and Geoenvironmental Engineering, 146(5), 05020002. 
Gallant, A. P., Shatnawi, E., Farouz, E., \& Jones, T. (2018). A case study of settlement and load transfer at depth beneath column-supported embankments. In IFCEE 2018 (pp. 337-351).

Gartung, E., Verspohl, J., Alexiew, D., \& Bergmair, F. (1996). Geogrid reinforced railway embankment on piles-Monitoring. Geosynthetics: Applications, Design and Construction.

Goughnour, R., \& Barksdale, R. (1984). Performance of a stone column supported embankment.

Guido, V. (1987). Plate loading tests on geogrid-reinforced earth slab. Geosynthetic'87 Conf., 216-225.

Hardin, B. O., \& Black, W. (1969). Closure on vibration modulus of normally consolidated clay. Journal of Soil Mechanics \& Foundations Div.

Hewlett, W., \& Randolph, M. (1988). Analysis of piled embankments. International Journal of Rock Mechanics and Mining Sciences and Geomechanics Abstracts, 25(6), 297-298.

Hillerborg, A., Modéer, M., \& Petersson, P.-E. (1976). Analysis of crack formation and crack growth in concrete by means of fracture mechanics and finite elements. Cement and Concrete Research, 6(6), 773-781.

Holdgate, G., \& Norvick, M. (2017). Geological evolution of the Holocene Yarra Delta and its relationship with Port Phillip Bay. Australian Journal of Earth Sciences, 64(3), 301-318.

Hong, W. P., Lee, J. H., \& Lee, K. W. (2007). Load transfer by soil arching in pile-supported embankments. Soils and Foundations, 47(5), 833-843.

Hoppe, E. J., Hite, S. L., \& others. (2006). Performance of a pile-supported embankment. Virginia Transportation Research Council.

Hosseinpour, I., Almeida, M. S., Riccio, M., \& Baroni, M. (2017). Strength and compressibility characteristics of a soft clay subjected to ground treatment. Geotechnical and Geological Engineering, 35(3), 1051-1066. 
Hosseinpour, I., Soriano, C., \& Almeida, M. S. (2019). A comparative study for the performance of encased granular columns. Journal of Rock Mechanics and Geotechnical Engineering, 11(2), 379388.

Hsi, J. (2001). Timber-piled embankments over soft ground. International Conference on Soil Mechanics and Geotechnical Engineering, 2085-2088.

Hsieh, P.-G., \& Ou, C.-Y. (1998). Shape of ground surface settlement profiles caused by excavation. Canadian Geotechnical Journal, 35(6), 1004-1017.

Huang, Z., Ziotopoulou, K., \& Filz, G. M. (2020). 3D Numerical Analyses of Column-Supported Embankments: Failure Heights, Failure Modes, and Deformations. Journal of Geotechnical and Geoenvironmental Engineering, 146(12), 04020141.

Jamsawang, P., Phongphinittana, E., Voottipruex, P., Bergado, D. T., \& Jongpradist, P. (2019). Comparative performances of two-and three-dimensional analyses of soil-cement mixing columns under an embankment load. Marine Georesources \& Geotechnology, 37(7), 852-869.

Japan Road Association. (2012). Guide for road embankment construction—Earth works for road. Tokyo, Japan.

King, D. J., Bouazza, A., Gniel, J. R., Rowe, R. K., \& Bui, H. H. (2017). Serviceability design for geosynthetic reinforced column supported embankments. Geotextiles and Geomembranes, 45(4), $261-279$.

King, D. J., Bouazza, A., Gniel, J. R., Rowe, R. K., \& Bui, H. H. (2018). Geosynthetic reinforced column supported embankments and the role of ground improvement installation effects. Canadian Geotechnical Journal, 55(6), 792-809.

Kitazume, M., \& Maruyama, K. (2006). External stability of group column type deep mixing improved ground under embankment loading. Soils and Foundations, 46(3), 323-340. 
Kitazume, M., \& Maruyama, K. (2007). Internal stability of group column type deep mixing improved ground under embankment loading. Soils and Foundations, 47(3), 437-455.

Lambe, T. W., \& Whitman, R. V. (1991). Soil mechanics (Vol. 10). John Wiley \& Sons.

Lin, K. Q., \& Wong, I. H. (1999). Use of deep cement mixing to reduce settlements at bridge approaches. Journal of Geotechnical and Geoenvironmental Engineering, 125(4), 309-320.

Liu, H., Kong, G., Chu, J., \& Ding, X. (2015). Grouted gravel column-supported highway embankment over soft clay: Case study. Canadian Geotechnical Journal, 52(11), 1725-1733.

Liu, H., Ng, C. W., \& Fei, K. (2007). Performance of a geogrid-reinforced and pile-supported highway embankment over soft clay: Case study. Journal of Geotechnical and Geoenvironmental Engineering, 133(12), 1483-1493.

Liu, H.-L., Chu, J., \& Deng, A. (2009). Use of large-diameter, cast-in situ concrete pipe piles for embankment over soft clay. Canadian Geotechnical Journal, 46(8), 915-927.

Liu, S.-Y., Du, Y.-J., Yi, Y.-L., \& Puppala, A. J. (2012). Field investigations on performance of T-shaped deep mixed soil cement column-supported embankments over soft ground. Journal of Geotechnical and Geoenvironmental Engineering, 138(6), 718-727.

Liu, W., Qu, S., Zhang, H., \& Nie, Z. (2017). An integrated method for analyzing load transfer in geosynthetic-reinforced and pile-supported embankment. KSCE Journal of Civil Engineering, 21(3), 687-702.

Maatkamp, T. (2016). The capabilities of the Plaxis Shotcrete material model for designing laterally loaded reinforced concrete structures in the subsurface.

McGuire, M. P. (2011). Critical height and surface deformation of column-supported embankments [PhD Thesis]. Virginia Tech.

McGuire, M., Sloan, J., \& Filz, G. (2020). Effectiveness of geosynthetic reinforcement for load transfer in column-supported embankments. Geosynthetics International, 27(2), 200-218. 
Nunez, M., Briançon, L., \& Dias, D. (2013). Analyses of a pile-supported embankment over soft clay: Full-scale experiment, analytical and numerical approaches. Engineering Geology, 153, 53-67.

Russell, D., Naughton, P., \& Kempton, G. (2003). A new design procedure for piled embankments. Proceedings of the 56th Canadian Geotechnical Conference and 2003 NAGS Conference, 1, 858865.

Russell, D., \& Pierpoint, N. (1997). An assessment of design methods for piled embankments. Ground Engineering, 30(10).

Schaefer, V., Berg, R., Collin, J., Christopher, B., DiMaggio, J., Filz, G., Bruce, D., \& Ayala, D. (2017). Ground modification methods reference manual—Volume II. Washington, DC: Federal Highway Administration.

Schanz, T., Vermeer, P., \& Bonnier, P. (1999). The hardening soil model: Formulation and verification. Beyond 2000 in Computational Geotechnics, 281-296.

Sloan, J. A., McGuire, M. P., \& Gallant, A. P. (2019). Load displacement compatibility method for design of column-supported embankments: Comparison to case histories. Geo-Congress 2019: Data, Software, Education, and a Tribute to Ralph Peck, 37-47.

Sloan, J., Filz, G., \& Collin, J. (2013). Field-scale column-supported embankment test facility. Geotechnical Testing Journal, 36(6), 891-902.

Stewart, M. E., Navin, M. P., \& Filz, G. M. (2004). Analysis of a column-supported test embankment at the I-95/Route 1 interchange. In Geotechnical engineering for transportation projects (pp. 13371346).

Tassios, T. P., \& Vintzēleou, E. N. (1987). Concrete-to-concrete friction. Journal of Structural Engineering, 113(4), 832-849.

Terzaghi, K., Peck, R. B., \& Mesri, G. (1996). Soil mechanics in engineering practice. John Wiley \& Sons. 
Van Eekelen, S., \& Bezuijen, A. (2014). Is $1+1=2$ ? Results of 3D model experiments on piled embankments. 10th International Conference on Geosynthetics (IGS-2014).

Van Eekelen, S., Bezuijen, A., \& Van Tol, A. (2013). An analytical model for arching in piled embankments. Geotextiles and Geomembranes, 39, 78-102.

Van Eekelen, S., Bezuijen, A., \& Van Tol, A. (2015). Validation of analytical models for the design of basal reinforced piled embankments. Geotextiles and Geomembranes, 43(1), 56-81.

Vardanega, P. J., \& Bolton, M. D. (2013). Stiffness of clays and silts: Normalizing shear modulus and shear strain. Journal of Geotechnical and Geoenvironmental Engineering, 139(9), 1575-1589.

Voottipruex, P., Bergado, D., Suksawat, T., Jamsawang, P., \& Cheang, W. (2011). Behavior and simulation of deep cement mixing (DCM) and stiffened deep cement mixing (SDCM) piles under full scale loading. Soils and Foundations, 51(2), 307-320.

Wachman, G., Biolzi, L., \& Labuz, J. F. (2010). Structural behavior of a pile-supported embankment. Journal of Geotechnical and Geoenvironmental Engineering, 136(1), 26-34.

Wang, A., \& Zhang, D. (2020). Lateral Response and Failure Mechanisms of Rigid Piles in Soft Soils Under Geosynthetic-Reinforced Embankment. International Journal of Civil Engineering, 18(2), $169-184$.

Wu, J., Ye, X., Li, J., \& Li, G. (2019). Field and numerical studies on the performance of high embankment built on soft soil reinforced with PHC piles. Computers and Geotechnics, 107, 1-13.

Yapage, N., Liyanapathirana, D., Kelly, R. B., Poulos, H. G., \& Leo, C. J. (2014). Numerical modeling of an embankment over soft ground improved with deep cement mixed columns: Case history. Journal of Geotechnical and Geoenvironmental Engineering, 140(11), 04014062.

Yu, X., Zheng, G., Zhou, H., \& Chai, J. (2021). Influence of geosynthetic reinforcement on the progressive failure of rigid columns under an embankment load. Acta Geotechnica, 1-8. 
Yun-Min, C., Wei-Ping, C., \& Ren-Peng, C. (2008). An experimental investigation of soil arching within basal reinforced and unreinforced piled embankments. Geotextiles and Geomembranes, 26(2), $164-174$. 